\title{
Situation variation in consumer benefit salience: theory and implications for consumer-firm interaction in the health domain
}

Citation for published version (APA):

Wendel, S. (2007). Situation variation in consumer benefit salience: theory and implications for consumerfirm interaction in the health domain. [Doctoral Thesis, Maastricht University]. Universiteit Maastricht. https://doi.org/10.26481/dis.20070426sw

Document status and date:

Published: 01/01/2007

DOI:

10.26481/dis.20070426sw

Document Version:

Publisher's PDF, also known as Version of record

Please check the document version of this publication:

- A submitted manuscript is the version of the article upon submission and before peer-review. There can be important differences between the submitted version and the official published version of record.

People interested in the research are advised to contact the author for the final version of the publication, or visit the DOI to the publisher's website.

- The final author version and the galley proof are versions of the publication after peer review.

- The final published version features the final layout of the paper including the volume, issue and page numbers.

Link to publication

\footnotetext{
General rights rights.

- You may freely distribute the URL identifying the publication in the public portal. please follow below link for the End User Agreement:

www.umlib.nl/taverne-license

Take down policy

If you believe that this document breaches copyright please contact us at:

repository@maastrichtuniversity.nl

providing details and we will investigate your claim.
}

Copyright and moral rights for the publications made accessible in the public portal are retained by the authors and/or other copyright owners and it is a condition of accessing publications that users recognise and abide by the legal requirements associated with these

- Users may download and print one copy of any publication from the public portal for the purpose of private study or research.

- You may not further distribute the material or use it for any profit-making activity or commercial gain

If the publication is distributed under the terms of Article $25 \mathrm{fa}$ of the Dutch Copyright Act, indicated by the "Taverne" license above, 
Situation Variation in Consumer Benefit Salience:

Theory and Implications for Consumer-Firm Interaction in the Health Domain 
Situation Variation in Consumer Benefit Salience:

Theory and Implications for Consumer-Firm Interaction in the Health Domain

(C) 2007, Sonja Wendel, Rotterdam.

All rights reserved. No part of this publication may be reprinted or utilized in any form or by any electronic, mechanical or other means, now known, or hereafter invented, including photocopying and recording, or in any information storage or retrieval system, without permission from the copyright owner.

ISBN: 978-90-9021713-0

Cover Design: Ton van den Broek

Printed by: Datawyse Maastricht 
Situation Variation in Consumer Benefit Salience:

Theory and Implications for Consumer-Firm Interaction in the

Health Domain

\section{PROEFSCHRIFT}

ter verkrijging van de graad van doctor aan de Universiteit Maastricht, op gezag van de Rector Magnificus, Prof. Mr. G.P.M.F. Mols, volgens het besluit van het College van Decanen, in het openbaar te verdedigen op donderdag 26 april 2007 om 12.00 uur

door

Sonja Wendel 


\section{Promotor}

Prof. dr. ir. B.G.C. Dellaert

\section{Beoordelingscommissie}

Prof. dr. J.C. de Ruyter (voorzitter)

Prof. dr. M.G. Heijltjes

Prof. dr. ir. J.C.M. van Trijp 
Für meine lieben Eltern

und meine Oma 

ACKNOWLEDGEMENTS 
The process of writing a dissertation should never be underestimated. In my case, it proved to be a process shaped by countless ups and downs. Thus, without the necessary intrinsic motivation and the assistance and support of many others, I would never have accomplished all of the tasks associated with writing this dissertation. In this sense, then, I am standing on the shoulders of giants. As Samuel Taylor Coleridge (1828) observed: "The dwarf sees farther than the giant, when he has the giant's shoulder to mount on."

First, I am grateful to my supervisor Professor Benedict Dellaert. Benedict's positive outlook on life, which is undoubtedly reflected in his work philosophy, certainly had a contagious effect on me. I remember the numerous times when I entered his office, thinking how hopeless my work was and how little progress I had made. Yet, my pessimistic thinking was proven to be wrong (at least most of the time) and I left his office with hope and optimism. This is unquestionably related to Benedict's passion for research. Benedict always supported me, on a conceptual as well as on a methodological level.

Furthermore, I would like to thank the members of the graduation committee, Professor Ko de Ruyter, Professor Marielle Heijltjes, and Professor Hans van Trijp for their time and effort! I am particularly thankful to Ko who was always there when I was in need of help and who encouraged and supported me in planning my stay abroad at the University of Georgia. Additionally, I am grateful to Professor Jos Lemmink, who believed in my capabilities and who brought me in contact with Benedict. Also, I would like to send a thank you across the Atlantic to Professor George Zinkhan. His endless patience, expertise of countless research streams, and encouraging words concerning the relevance of my research, made my stay at the University of Georgia a memorable experience.

Special thanks also go to the members of the Department of Marketing at Maastricht University and to my new colleagues at the Erasmus University Rotterdam. In particular, I would like to thank Professor Stefan Stremersch for his understanding and support. A special thank you also goes to Mirella Kleijnen. From tutor, to colleague, to roommate, to being a wonderful friend. I highly appreciate her belief in my capabilities and encouraging words throughout the entire Ph.D. progress. Her support has been, and as a matter of fact is still endless! Also, special 
thanks go to Roger Pruppers and Ingrid Beckers. Thanks for always showing sincere interest, for all the conversations we've had (and still have), and just for always being there! Furthermore, I would like to thank Professor Martin Wetzels, Dr. Bas Donkers, Dr. Ad de Jong, and Dr. Sandra Streukens who always answered any statistical question of mine right on the spot.

Another thank you is send across the Atlantic to Marie and Robert Hull. The blend of Marie's persistence and never-ending patience in teaching me how to accurately speak and write English are highly appreciated. I still hear her say: drop the 'or' and add the 'will'. A special thank you also goes to my wonderful friends. First, I would like to mention Semhar Haile. Her positivism and ability to make me see things in a very different light have helped me tremendously. Thank you! Also, I would like to thank Oliver Wurtz, Thomas Dittmar, Markus Bauer, Anke Rathgeber, Sabine Almansa, Oliver Almansa, Christiane John, and Ulrich John. It is a comforting feeling knowing that you are there!

Finally, an exceptional thank you goes to two families. First, I would like to thank the entire family van den Broek: Freek, Juli-anne, Ton, Nynke, Pepijn, and Fridoline van den Broek. Their support throughout the time of my promotion and beyond was endless and helped me put things into perspective, which I am grateful for. I especially would like to thank Freek van den Broek. I particularly thank Freek for his patience, moral support, and for always being there! I would not have mastered this without him by my side. Herewith, I also would like to thank Ton for the design of the cover of this dissertation.

A final BIG thank you goes to my whole family! First, a special thank you goes to my cousin Steffen Ehemann for being one of the paranimfen. Secondly, I am expressing my gratitude to my parents and also to Dr. Horst Bruder. Their kind and encouraging words during endless talks have given me the necessary strength and positive attitude during the process of writing this dissertation. It is wonderful to have people in your life that believe in you. Ein herzliches Dankeschön geht auch an meine Oma, die mich wirklich in jeder Hinsicht unterstützt hat und die es mit nur wenigen Worten doch immer schafft, mich auf den Boden der Tatsachen zurückzubringen! Danke. 

TABLE OF CONTENTS 


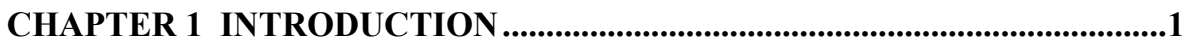

$1.1 \quad$ PRELUDE

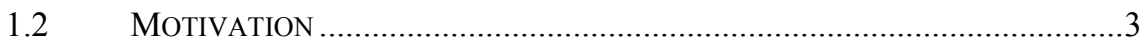

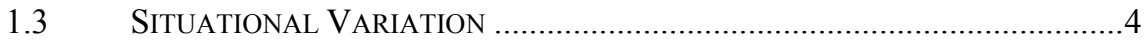

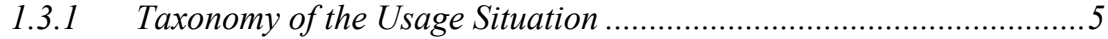

1.3.2 Substitution-in-Use Approach ....................................................... 6

1.3.3 Joint Role of Usage Situation and Consumer Benefits ....................... 7

1.4 OBJECTIVES ACROSS THE DifFERENT STUDIES ........................................

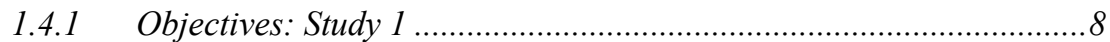

1.4.2 Objectives: Study 2 .................................................................. 8

1.4.3 Objectives: Study 3 .................................................................... 9

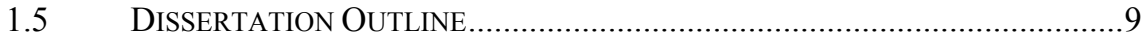

CHAPTER 2 SITUATION VARIATION IN CONSUMERS' MEDIA

CHANNEL CONSIDERATION .....................................................................11

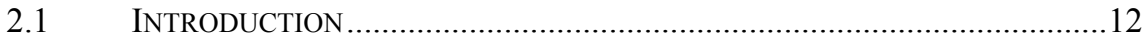

2.2 CONSUMERS' MEDIA CHANNEL CONSIDERATION ...................................13

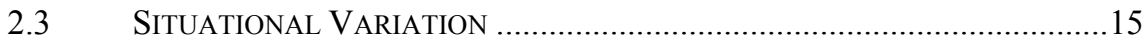

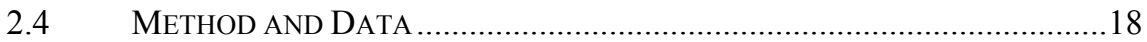

2.4.1 Measurement Approach .................................................................19

2.4.2 Sample Characteristics ...................................................................21

2.4.3 Analysis and Econometric Model ................................................22

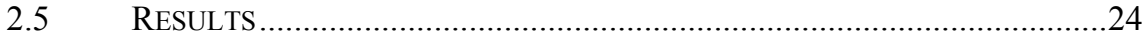

2.5.1 Media Channel Consideration Model...............................................24

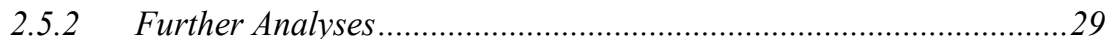

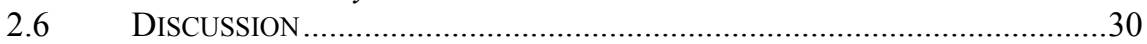

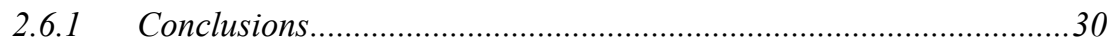

2.6.2 Theoretical and Managerial Implications ..................................... 30

2.6.3 Limitations and Directions for Further Research............................. 31

\section{CHAPTER 3 SITUATION-BASED SHIFTS IN CONSUMER BENEFIT} SALIENCE: THE JOINT ROLE OF AFFECT AND COGNITION .................33

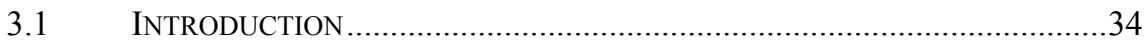

3.2 SITUATION VARIATION AND BENEFIT SALIENCE ......................................35

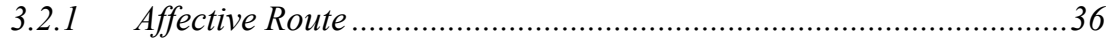

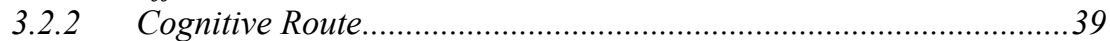

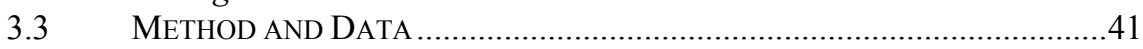

3.3.1 Participants and Design ........................................................... 41

3.3.2 Measurement Affective States ...................................................... 43

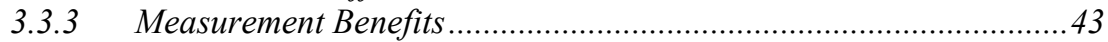

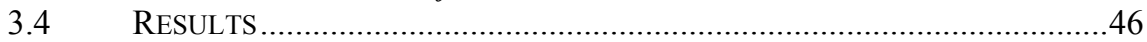

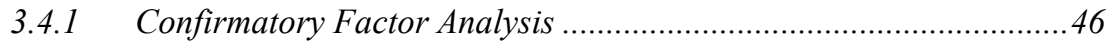

3.4.2 Hypothesis Testing........................................................... 47

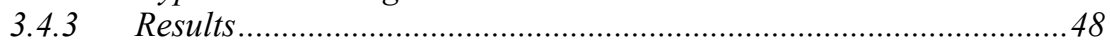




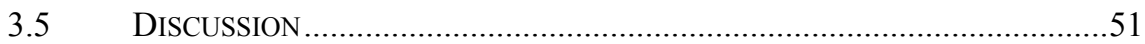

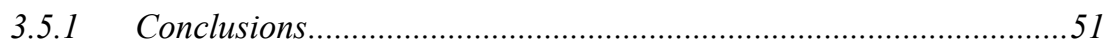

3.5.2 Theoretical and Managerial Implications .....................................51

3.5.3 Limitations and Directions for Further Research ..........................52

CHAPTER 4 PERSONALIZED HEALTH RECOMMENDATION SYSTEMS: CONSUMER BENEFIT TRADE-OFFS ACROSS SYSTEM STAGES AND CHANNEL CONTEXTS .....................................................55

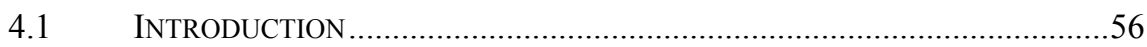

4.2 CONSUmer Perspectives on Personalized Health

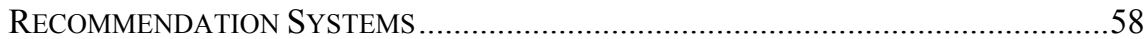

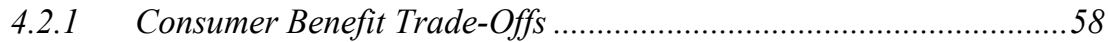

4.2.2 Stages of Personalized Health Recommendation Systems ................60

4.2.3 Channel Context and Benefit Trade-Offs ........................................6 63

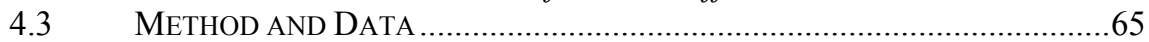

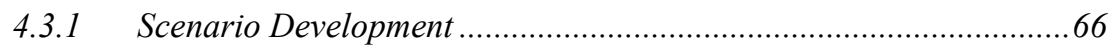

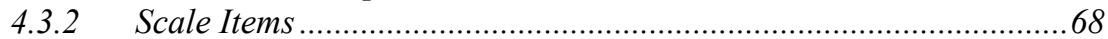

4.3.3 Main Study: Sample and Procedure ................................................. 70

4.3.4 Analysis Approach ......................................................................... 70

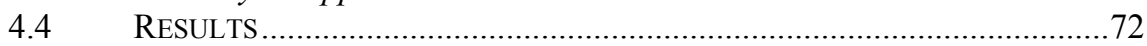

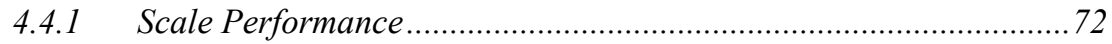

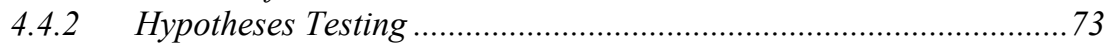

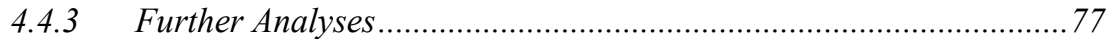

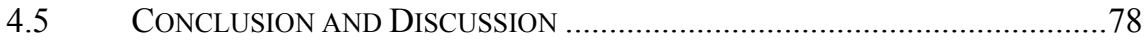

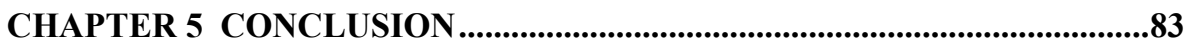

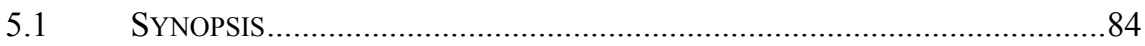

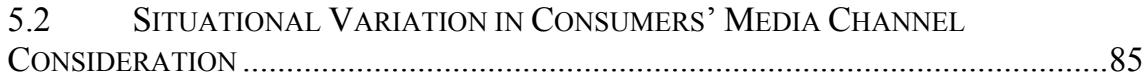

5.3 CONSUMER BENEFIT SALIENCE ……................................................. 86

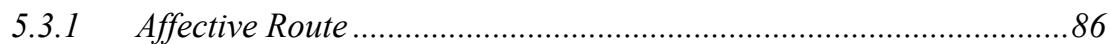

5.3.2 Cognitive Route......................................................................... 87

5.4 CONSUMER BeNEFIT TRADE-OFfS ACROSS System StAGES AND

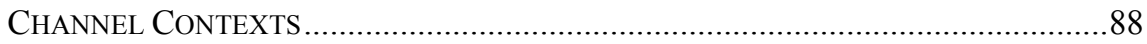

5.5 LIMITATIONS AND FUTURE RESEARCH SUGGESTIONS ...........................89

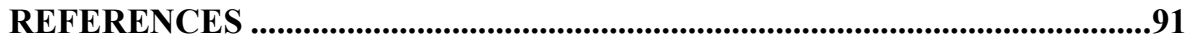

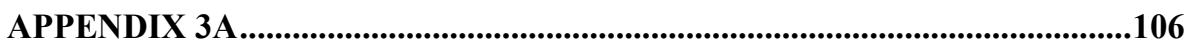

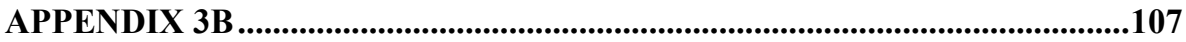

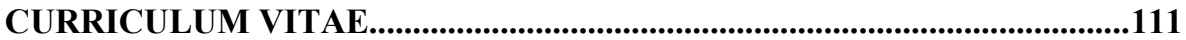



Chapter 1

\section{INTRODUCTION}




\subsection{Prelude}

Firms have been criticized for failing to "get inside the lives of their customers" or think in terms of meaningful scenarios for these customers (Seybold 2001), even though firms that can put themselves into the shoes of their customers are more likely to address customer needs and experiences more effectively. Such skillful comprehension of consumers' needs specifically involves strong representations of the particular situations that are relevant to those customers.

For instance, imagine yourself in the following communication situation:

One afternoon, while you are having lunch at home, you hear on the radio an announcement of a food scare. Seemingly, a product ingredient of the major food manufacturer XY has been contaminated. You want to find out more about the specific products that have been contaminated and possible health consequences.

There are various ways you might consider gathering information about this food scare. For example, you might:

1) Search the Web site of the food manufacturer,

2) Search a news Web site (e.g., CNN),

3) Search the Web site of the Ministry of Health,

4) Call a representative of the Ministry of Health, or

5) Call a representative of the food manufacturer (e.g., 1-800 service numbers).

This, by no means exhaustive list of communication sources available for retrieving information, illustrates the various possible channels companies and consumers may use to engage in dialogue. Depending on the benefits and costs involved in using each channel (e.g., some channels are more convenient, timeefficient, and trustworthy than others), people will choose the channel that best fits their needs in that particular situation. For example, in the food scare scenario, you likely value up-to-date and trustworthy sources for retrieving information. Assuming 
that you have Internet access at home, you might consider visiting the CNN Web site and/or the Web site of the Ministry of Health, two sources that you believe provide up-to-date and trustworthy information. Companies that are skilled in thinking in terms of hypothetical customer scenarios can use a similar method to address the information needs of their customers more effectively. In line with this conceptualization, this dissertation focuses mainly on the situation as a driver of when and how firms and consumers connect in the communication process.

\subsection{Motivation}

During the past decade, many firms have spent considerable efforts to enhance their relationships with customers. However, when analyzing consumer behavior with respect to their own products and services, firms have ignored the broader context (i.e., situation) in which consumers make choices when they buy and use products and services (Seybold 2001). Although a substantial amount of research has attempted to understand the impact of situation on consumer preferences/choices/considerations (e.g., Belk 1974, 1975; Ratneshwar and Shocker 1991; Srivastava, Leone, and Shocker 1981; Warlop and Ratneshwar 1993), few studies investigate the role of situation for marketing. In addition, virtually no studies have examined the impact of situational effects within the context of communication. This neglect represents a particular challenge in the field of marketing because of the rapidly increasing availability of various communication channels to consumers. Interactive new media such as the Internet and mobile devices make it possible to deliver more tailored products, services, and information to consumers at relatively low costs - an advancement that has greatly increased the opportunities for firms to communicate directly with their consumers (e.g., Ghosh 1998) and enabled them to address the unique situational demands and needs of their customers far more easily (Kenny and Marshall 2000).

One important type of firm-consumer communication for which the Internet increasingly is being used pertains to product information exchanges. The following example from Johnson \& Johnson (J\&J) illustrates how thinking contextually (i.e., situation-specific thinking) can be valuable for communicating 
with consumers. At one point, the company realized that its communication via the Internet about specific product information (e.g., headache remedies, skin care products) would not be sufficient to connect to potential customers. As a result, J\&J decided to place banner advertisements for headache relievers on e-brokers' Web sites every time the stock market fell by more than 100 points. This example illustrates how thinking in terms of customer scenarios (in this case, in a digital situation) can be a valuable tool for delivering the right message at the right time to the right consumers (Kenny and Marshall 2000).

As mentioned previously, despite the considerable evidence of the impact of a usage situation on consumer behavior (e.g., Belk, 1974, 1975; Warlop and Ratneshwar 1993), this evidence has not been translated into the terms of consumerfirm communications, nor have the implications for marketing communications been investigated. Thus, this dissertation contributes to existing literature by examining situation as a key driver of when and how to connect firms and consumers in the communication process.

Moreover, the joint trends of consumers' increased awareness of food product ingredients and food manufacturing technology, as well as their impact on human health (e.g., Moorman and Matulich 1993), in combination with more and more active consumer search behavior in retrieving health information online (Madden and Fox 2006), presents unique challenges for the health sector. Thus, this dissertation uses the health sector as an area of application across three studies.

\subsection{SituATIONAL VARIATION}

Despite the growing role of the usage situation in defining consumer choice behavior, little research investigates its role in the context of marketing communications. This section provides an overview to describe current knowledge about consumers' usage situations from the more traditional perspective of consumer product choice. First, it offers an overview of the taxonomy of usage situation. Second, it briefly reviews the substitution-in-use (SIU) approach, which focuses on consumers' perceptions of the similarity in product-usage patterns across 
different usage situations. Third, it addresses the joint role of usage situation and consumer benefits in consumer choice behavior.

\subsubsection{TAXONOMY OF THE USAGE SitUATION}

Initially, research applications that incorporated usage situational influences were limited by the lack of a comprehensive taxonomy of situational characteristics. The seminal work in this area defined situation, as proposed by Belk $(1974,1975)$, on the basis of objective measures. Belk defined the term situation as "all those factors particular to a time and place of observation, which do not follow from personal (intra-individual) and stimulus (choice alternative) attributes, and which have a demonstrable and systematic effect on behavior" (1974, 157). In operationalizing this definition, he distinguished the following five dimensions of a consumption situation (Belk 1975):

1) Physical surroundings: The most effortlessly observed characteristics of a situation, such as the weather, décor, sounds, and so forth;

2) Social surroundings: More detailed information about others around the individual, such as the presence of other people, their characteristics, and their role;

3) Temporal perspective: Refers to the arrangement of events in time and can be specified in different units, such as time of day or the number of weeks between events;

4) Task definition: The intent to select, purchase, or get information about a purchase (e.g., buying a birthday gift); and

5) Antecedent states: Momentary moods such as anxiety or momentary conditions such as illness rather than chronic individual traits.

Lutz and Kakkar (1975) added to Belk’s work a subjective (psychological) perspective and stressed that the definition of a situation must depend on the consumers' perception of the situational dimensions. Specifically, they applied a theory that originated in environmental psychology (Mehrabian and Russell 1974) to develop their framework. This framework is based on three internal state 
variables - pleasure, arousal, and dominance - that mediate the influence of the situation on behavior. Their particular definition of situation is as follows:

"The situation relevant for the understanding of consumer behavior is the psychological situation, which may be defined as an individual's internal responses to, or interpretation of, all factors particular to a time and place of observation which are not stable intra-individual characteristics or stable environmental characteristics, and which have a demonstrable and systematic effect on the individual's psychological processes and/or overt behavior" (Lutz and Kakkar 1975, 441).

This view complements the objective measurement approach that restricts itself to features of the situation present before a consumer interprets the situation (Belk 1974).

\subsubsection{Substitution-IN-USE APPROACH}

Consumers' substitution in use (SIU) with regard to products and the perceived similarity of product-usage patterns represents another research stream of relevance for the situational differences in consumer choice (Srivastava, Alpert, and Shocker 1984; Srivastava et al. 1981). In this approach, "one uses judgmental data to depict how customers perceive a broadly defined set of product alternatives and to examine how those alternatives relate to specific product usage contexts or usages" (Ratneshwar and Shocker 1991, 281). Therefore, this approach implies that products should be perceived as similar when they are perceived as substitutable for the same usages. In addition, the usage context (i.e., situation) acts as a constraint that identifies the consumer benefits (or bundles of benefits) appropriate in the specific situation and therefore restricts the means (products) by which a consumer may attain his or her specific ends. Empirical research in this stream supports this line of argumentation and has produced quite robust results (Belk 1974; Ratneshwar and Shocker 1991). For example, Ratneshwar and Shocker (1991) state that, according to the consumer's usage situation, certain product benefits might be made salient 
when they are triggered by relevant schemata stored in that consumer's memory. Consequently, products that possess these benefits might be retrieved from memory.

\subsubsection{Joint Role of Usage Situation ANd Consumer BeNEFITS}

The notion that the benefits that products possess are basic to consumer choice has been well documented. Moreover, that the benefits consumers desire in products may differ across usage situations, and therefore that variations in benefits may offer a possible explanation for the observed effects of the usage context on consumer choice, has led to a third line of situation-related research (e.g., Miller and Ginter 1979; Ratneshwar et al. 1997; Warlop and Ratneshwar 1993). According to Warlop and Ratneshwar (1993) and Sinha (1994), differences exist in the role of benefits in consumer decision processes, depending on how familiar the situation is to the consumers. For instance, Warlop and Ratneshwar (1993) investigate the role of the usage situation in consumer choice and find evidence that consumers' retrieval of goal-related information (e.g., benefits) differs when they are presented with familiar versus unfamiliar usage situations. Ratneshwar et al. (1997) also state that a product benefit may be more or less salient in consumers' minds depending on the particular usage situation. Thus, we find conclusive evidence that the situational context facilitates consumers' identification of specific benefits that are pertinent to a particular situation. We therefore start from the assertion that a similar process occurs in the context of consumer-firm interactions; namely, the situation influences the benefits that consumers look for in their search for information.

\subsection{ObJeCtives ACross the Different Studies}

The overall objective of this dissertation is to provide profound insights into the impact of the usage situation as a key driver of when and how firms and consumers connect during the communication process. The first study, presented in Chapter 2, focuses on consumers' considerations of media channels across different usage situations. We investigate which media channels consumers relate to specific goals, expressed as benefits, and manipulate the usage situation as these consumers search for information. The second study, discussed in Chapter 3, follows up on the 
results of the first and investigates how situational differences in the salience of the benefits arise. The final study in Chapter 4 explores consumers' evaluations of consumer-firm interactions that were designed to create and deliver personalized health recommendations. Again, we emphasize the impact of the situation on consumers' evaluations of such a system. The following sections outline these three studies in more detail.

\subsubsection{OBJeCtives: STUdy 1}

A vast amount of studies have documented the impact of the usage situation on consumer choice behavior (e.g., Srivastava et al. 1981, 1984). Yet, to our knowledge, no research explores situational differences in consumers' choices/preferences/considerations across various media channels (traditional versus new). The increase in communication channels (e.g., new media such as the Internet) in particular has given rise to the issue of consumer media channel consideration, which may rely on consumers' differing goals, as well as their media channel consideration in a particular communication situation. Therefore, this study investigates consumers' consideration of different media channels and manipulates the usage situation they encounter during their search for information.

\subsubsection{OBJECTIVES: STUDY 2}

In Study 2, we explore the underlying mechanism by which situational differences affect benefit salience. As emphasized previously, the influence of situational differences on consumer behavior (e.g., Belk 1974; Lutz and Kakkar 1975) and the benefits that consumers look for in products and channels vary across usage situations have been well documented (e.g., Gutman 1982; Srivastava et al. 1984). Yet only a few studies have explored the underlying mechanism by which the situation affects consumers' benefit salience (Lutz and Kakkar 1975). In response, this study investigates how specific benefits become salient in consumers' minds across various usage situations. Specifically, it jointly investigates two routes (affective and cognitive) by which the situation may influence consumers' benefit salience. It also explores the nature of consumer responses in the relatively new 
information medium of the Internet. From within this Internet context, we focus on consumer information search.

\subsubsection{OBJECTIVES: STUDY 3}

Sophisticated consumer databases and marketing information systems allow for personalization in many consumer-firm interactions (e.g., Steckel et al. 2005). Marketing research pertaining to personalized recommendations has focused largely on how consumers make product or service choices when they use recommendation systems (e.g., Diehl, Kornish, and Lynch 2003; Häubl and Trifts 2000) or the development of new methods to improve the quality of those recommendations (e.g., Ansari, Essegaier, and Kohli 2000). However, little is known about the motivation and drivers consumers experience to adopt and use such personalized recommendation systems. Therefore, with this study, we contribute to existing literature by investigating the benefit trade-offs that consumers must make to evaluate such a personalized system. We further explore to what extent the channel context (medical versus non-medical) moderates the impact of consumers' benefit evaluations and their use of the system.

\subsection{Dissertation OUTLINE}

This dissertation addresses three different studies in Chapters 2, 3, and 4, as depicted in Table 1-1. All three studies interrelate; they examine the situation or usage context as a key driver that connects firms and consumers in a communication process. We make use of different theoretical research streams across these studies to address our research objectives. All studies apply to the health field and in particular to food products. 


\section{Table 1-1 Overview of the Three Studies of this Dissertation}

\begin{tabular}{llll}
\hline \hline Chapter & Study & Objective & Context \\
\hline 1 & Introduction & $\begin{array}{l}\text { Explain consumers' media channel } \\
\text { Ctudy 1: Situation Variation in } \\
\text { Consumers' Media Channel } \\
\text { consideration as a function of the } \\
\text { channels' perceived benefits and } \\
\text { different usage situations. }\end{array}$ & $\begin{array}{l}\text { Food } \\
\text { products }\end{array}$ \\
\hline 3 & $\begin{array}{l}\text { Study 2: Situation-Based Shifts } \\
\text { in Consumers' Benefit Salience: } \\
\text { The Joint Role of Affect and } \\
\text { Cognition }\end{array}$ & $\begin{array}{l}\text { Explore the process by which } \\
\text { benefits become salient in } \\
\text { consumers' minds across various } \\
\text { usage situations. }\end{array}$ & $\begin{array}{l}\text { Food } \\
\text { products }\end{array}$ \\
\hline 4 & $\begin{array}{l}\text { Study 3: Personalized Health } \\
\text { Recommendation Systems: } \\
\text { Consumers' Benefit Trade-Offs } \\
\text { Across System Stages and } \\
\text { Channel Contexts }\end{array}$ & $\begin{array}{l}\text { Explore the drivers and } \\
\text { motivations of consumers to adopt } \\
\text { and use a personalized health } \\
\text { recommendation system. }\end{array}$ & $\begin{array}{l}\text { Food } \\
\text { products }\end{array}$ \\
\hline 5 & Conclusion & & \\
\hline \hline
\end{tabular}

Study 1 (Chapter 2) addresses consumers' consideration of media channels by investigating which channels they find acceptable to use across different usage situations. The conceptual model contained therein describes consumers' media channel consideration as a function of the media channel's perceived benefits. Study 2 (Chapter 3) follows up on the results of Study 1 and further explores the underlying mechanism by which the situation affects consumers' benefit salience. In this case, we focus on two joint routes (affective and cognitive) to explain how the situation influences benefit salience. Study 3 (Chapter 4) explores the underlying motivation and drivers of consumers' adoption and use of a personalized recommendation system through a focus on consumers' benefit evaluations of a system. We further explore the moderating effect of channel context (medical versus non-medical) on consumers' willingness to use this system. Finally, Chapter 5 provides a discussion of the main findings across the three studies and concludes with various implications, limitations, and future research suggestions. 


\section{Chapter 2}

\section{SITUATION VARIATION IN CONSUMERS' MEDIA CHANNEL CONSIDERATION}

In this chapter, we investigate consumers' consideration of media channels in different usage situations using a model that explains consumers' media channel consideration as a function of the media channel's perceived benefits. In addition, we hypothesize that the usage situation affects consumers' media channel considerations and that situation-based benefit requirements moderate the effect of benefits on channel considerations. We test the hypothesized relationships using survey data from 341 consumers regarding their consideration of 12 different media channels used by manufacturers to communicate product information across three product-related usage situations. The results of the analyses support the proposed model structure and confirm the expected relationships among perceived media channel benefits, usage situations, media channel requirements, and consumers' media channel considerations.

\footnotetext{
${ }^{1}$ This chapter is largely based on Wendel, Sonja and Benedict G.C. Dellaert (2005), "Situation Variation in Consumers' Media Channel Consideration," Journal of the Academy of Marketing Science, 33 (Fall), $575-84$.
} 


\section{$2.1 \quad$ INTRODUCTION}

Recent advances in communication technology such as the Internet have changed managers' and consumers' ideas about how firms and customers should interact (e.g., Haeckel 1998; Watson et al. 2000); increasingly, consumers are viewed as active participants in supply chain value-creation processes (Wind and Rangaswamy 2001). An important consequence of this new perspective is that it has become more important for firms to provide their consumers with information about their offerings. In the case of online customization (e.g., Dell), consumers must be able to understand the details of many product variants to judge which variant is most suitable for them and provide their made-to-measure specifications (Huffman and Kahn 1998). In the case of food products, consumers need to understand how they can use the manufacturer's product enjoyably and safely.

In turn, manufacturers are faced with new questions about how to communicate with their consumers. First, in the context of specific media channels, how should product information be designed to communicate effectively with consumers? For example, recent research highlights the interactive nature of new media channels such as the Internet, as well as the requirements this interactivity places on communication design (Stewart and Pavlou 2002). Second, which media channels should be used to communicate with consumers? Even if product communications are well designed, they may be ineffective if the messages are sent through media channels that consumers do not consider.

We address this second question in the current chapter. In particular, we analyze consumers' consideration of media channels by investigating which channels they find acceptable. The concept of consideration has received ample attention in consumer choice literature (e.g., Roberts and Lattin 1997), which has shown that, for a brand to be chosen, it first must be included in the consumer's consideration set, which we define as the subset of brands for which a consumer makes an explicit utility comparison or cost-benefit trade-off analysis before making a brand choice (Mehta, Rajiv, and Srinivasan 2003). We propose that the concept of a consideration set can be extended to the field of media channels and 
investigate how consumers' media channel consideration relates to the communication benefits they perceive these various media channels to possess.

In our analysis, we also investigate the notion that consumers' consideration of media channels depends on the specific usage situation (Seybold 2001). This phenomenon has been well supported by previous work pertaining to the effect of situational variations on consumer preferences for products and services (Srivastava, Leone, and Shocker 1981). We hypothesize that situational differences in consumer preferences exist in consumers' media channel considerations and argue that the usage situation influences which benefits consumers require from a media channel. For example, in some situations, consumers may be more interested in media channels that are fast to use, whereas in others, they may find it more important that the channel provides very detailed information. Specifically, we expect that consumers' media channel consideration will shift according to the usage situation and that this shift is due to differences in the requirements they have for the media channels.

\subsection{Consumers' Media Channel Consideration}

The starting point for our conceptual model is the notion that media channels provide different benefits to consumers (Gutman 1982). In the context of product consumption, benefits are "the advantages that consumers enjoy from the consumption of products" (Gutman 1982, 61). Our focus is on the benefits that consumers enjoy from using alternative media channels, which we describe in terms of the advantages that consumers may perceive these various media channels to have (e.g., informative, time saving).

In theorizing about the formation of consumers' media channel consideration sets (i.e., the set of media channels that a consumer finds acceptable for use), we follow a cost-benefit approach (Roberts and Nedungadi 1995). With this approach, consideration set formation occurs as a process by which consumers consider the use of a certain media channel only if the benefits of including this channel in their consideration set exceed their individual threshold of consideration (Bronnenberg and Vanhonacker 1996). The individual threshold entails the various 
(cognitive and labor) costs associated with a detailed evaluation of the channel (Hauser and Wernerfelt 1990). An implicit assumption in this approach is that consumers engage in a relatively active consideration set formation process, in which they evaluate whether to include a media channel in their consideration set on the basis of the benefits they perceive that channel to have. Therefore, we expect that a media channel that provides more benefits is more likely to be included in the consumer's consideration set. In Figure 2-1, we graphically summarize this relationship, as well as the other hypotheses in our conceptual model.

H1: Media channels that have a greater number of benefits are more likely to be included in the consumer's consideration set.

\section{Figure 2-1 Conceptual Model of Consumers' Media Channel Consideration}

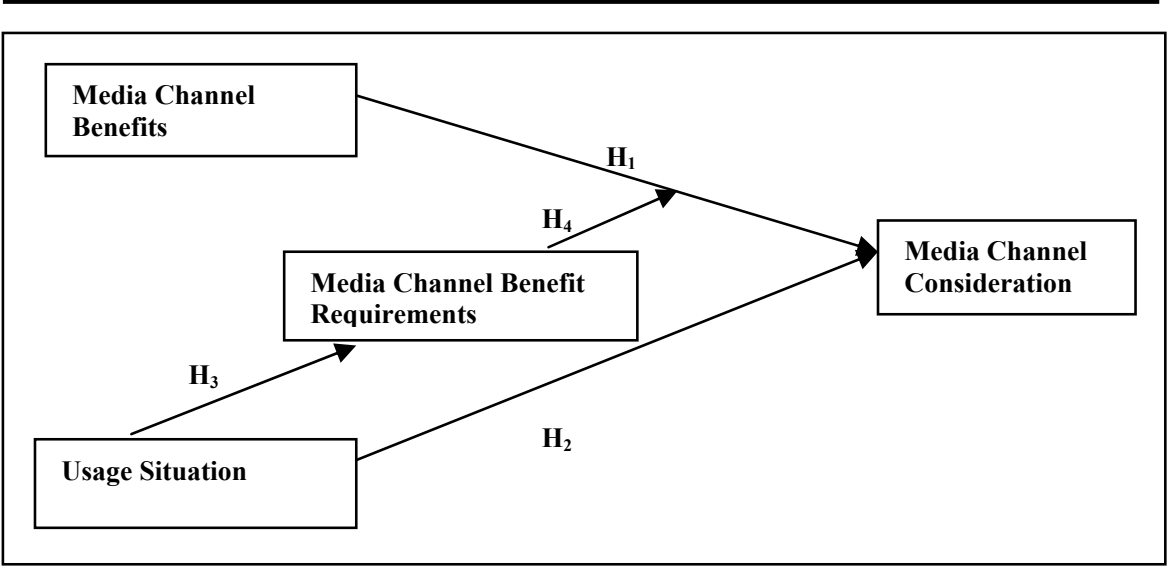

Notes: Media channel benefit requirements are hypothesized to depend on the consumers' usage situation (H3) and moderate the effect of perceived media channel benefits on media channel consideration (H4).

Other research has investigated consumer decision processes. For instance, Hoyer and Brown (1990) note that consumers may not always be aware of product or channel benefits or expend the cognitive effort to make benefit comparisons in their decision-making strategy and therefore may rely on simpler heuristics or habit. Swait and Adamowicz (2001) find that consumers simplify their product choice 
strategies by focusing on the brand's main effects, not specific product attributes. We expect that such a decision simplification rule may transfer to consumers' media channel consideration, in which case media channel consideration would be based mainly on relatively stable, media channel-specific intercepts and not be affected by media channel benefits. Therefore, we may find that we need to reject $\mathrm{H} 1$ in favor of an alternative model of media channel consideration in which media channel benefits are not actively evaluated.

\subsection{SitUATIONAL VARIATION}

We also address situational differences in consumers' media channel considerations. The influence of the usage situation on consumer preferences for products and services has been well documented in prior research on consumer behavior (Belk 1974, 1975; Srivastava, Alpert, and Shocker 1984). In line with Belk $(1974,157)$, we define a usage situation as "those factors particular to a time and place of observation, which do not follow from personal (intra-individual) and stimulus (choice alternative) attributes, and which have a demonstrable and systematic effect on current behavior."

Previous research, such as that by Ratneshwar and Shocker (1991), has investigated the impact of different usage contexts on consumer consideration sets and shown that consumers consider different products in different usage situations. These findings are in line with those of Warlop and Ratneshwar (1993), who illustrate the importance of the usage context (familiar versus unfamiliar situations) with regard to the formation of consideration sets. Also, Desai and Hoyer (2000) explore the effects of two specific usage situations - usage occasion frequency and usage location familiarity - on consideration sets and observe that memory-based consideration sets differ across situations. On the basis of these results, we expect that the usage situation will play a significant role in the context of consumers' media channel consideration. For example, searching for product information after the announcement of a food scare might lead a consumer to consider different media channels than would looking for product information about a new product that just was introduced into the market. 
H2: The usage situation affects which media channel a consumer considers.

A particularly relevant stream of research to explain the mechanism behind this hypothesized situational effect on consumers' media channel consideration is the substitution-in-use (SIU) approach (Ratneshwar and Shocker 1991; Srivastava et al. 1981). As we detailed in Chapter 1, a key insight from the SIU approach is that the benefits that consumers require a product to have vary across usage situations (i.e., consumer needs vary across usage situations). Srivastava et al. (1984) argue that consumers look specifically for the benefits that products provide rather than for the products themselves and emphasize the impact of the environment that surrounds the product and consumer. Over time, consumers may group products for consideration on the basis of the "perceived appropriateness of their functional attributes for the intended usage" (Srivastava et al. 1984, 32). This reasoning implies that products convey different benefits to consumers and that these benefits in turn may be demanded in different usage situations. The effect of the situation on consideration is supported by previous research that shows that the usage context helps consumers define the benefits they require from the product's use (e.g., Warlop and Ratneshwar 1993). Ratneshwar and Shocker (1991) build on the knowledge that consumers look for certain benefits when choosing their products to note that products can act as substitutes in a given usage situation if they fulfill the same benefits for which a consumer is searching. Gutman (1982) presents a model for a means-end chain analysis that incorporates the usage situation and argues that consumers consider the consequences (which also might be called benefits) according to the requirements of the situation. Thus, in line with Gutman (1982), we expect that consumers' benefit requirements depend on the demands of the situation. Finally, Ratneshwar et al. (1997) argue that product benefits can be more or less salient depending on the context of a particular usage situation (situational benefit salience).

Because the SIU approach (Ratneshwar and Shocker 1991; Srivastava et al. 1981), as well as other research on consumer benefit requirements (Gutman 1982; Myers 1976), provides evidence that consumer benefit requirements differ across 
usage situations, we hypothesize that the process by which usage situations affect consideration also operates in the context of media channels and therefore that the usage situation has a significant impact on consumers' benefit requirements for media channels. For example, in a usage situation in which a consumer is pressured for time, he or she will look for different media channel benefits to retrieve product information than he or she might in a usage situation whose purpose is to gather product information about DVD players for a future purchase. In the former usage situation, the consumer may require channel benefits such as time saving and ease of use, whereas in the latter, he or she may require channel benefits such as detailed information and trustworthiness.

H3: The usage situation affects which media channel benefits a consumer requires.

On the basis of the SIU approach, Srivastava et al. (1981) suggest that the use of a product depends on the match between the product's benefits and the requirements of the usage situation. That is, the process by which the usage situation affects product consideration proceeds through the importance that consumers attach to product benefits; this importance in turn is influenced by whether the consumers require this benefit in a given usage situation (e.g., Ratneshwar and Shocker 1991). In other words, the benefits that a consumer requires moderate the effect of those benefits on product use. Extending this argument to the context of consumers' media channel consideration, we expect that consumers' consideration depends on the match between the media channel benefits consumers perceive and those they require; the latter, of course, are driven by the usage situation. For example, if a consumer is confronted with a usage situation that involves time pressures (e.g., to retrieve product information after a food scare has been announced), he or she may require a media channel that takes little time to use. If this consumer perceives the Internet to be a media channel that saves time, he or she is more likely to consider the Internet in the given usage situation. 
H4: The media channel benefits that consumers require moderate the effect of those benefits on media channel consideration.

An alternative to $\mathrm{H} 4$ might state that the usage situation directly moderates the effect of media channel benefits on media channel consideration rather than indirectly through consumers' media channel benefit requirements. For example, if consumers are not able to express or differentiate their benefit requirements for different usage situations, the hypothesized moderating effect of benefit requirements may not occur. Consumer benefit requirements also could be stable for individual consumers and therefore not vary between usage situations, in which case these consumers may perceive the variations in their media channel requirements across usage situations as relatively minor. Therefore, in testing $\mathrm{H} 3$ and $\mathrm{H} 4$, we also evaluate an alternative model of consumers' media channel consideration in which we exclude the moderating effect of benefit requirements and instead test directly for the effect of the usage situation on media channel benefit requirements.

\subsection{Method ANd DATA}

The past decade has witnessed increased consumer awareness of the impact of food product ingredients and food manufacturing technology on human health. For example, Moorman and Matulich (1993) observe that consumers are increasingly sensitive to factors that affect their health. Other studies have shown that, at least in the United States, consumers' awareness of the role of diet and appropriate nutrition in self-medication and disease prevention is growing (e.g., Childs and Poryzees 1997; Sloan 1999). These trends present food manufacturers with increased challenges to communicate effectively with their consumers about food products' ingredients, as well as other aspects of their production processes.

Data for this project were collected as part of a larger survey conducted in cooperation with a food product manufacturer. The survey was administered to 453 consumers who were members of a large Internet-based panel of approximately 25,000 members. Respondents were selected from the panel on the basis of the criterion that they had the responsibility for food purchases in their household. Panel 
participants were informed about the survey by e-mail, and the survey Web link was closed after 453 responses were obtained. ${ }^{2}$ Additional respondents were directed to a page informing them that the survey was closed. Of these 453 respondents, 94 were not presented with questions regarding the usage situation, ${ }^{3}$ which gives us a sample of 341 for our analyses that involve usage situation-specific effects.

\subsubsection{MEASUREMENT APPROACH}

To measure respondents' perceptions of various media channel benefits, usage situation-specific benefit requirements, and media channel considerations, we constructed the survey on the basis of an association pattern technique (APT) approach (Ter Hofstede et al. 1998; Ter Hofstede, Steenkamp, and Wedel 1999). The APT approach originally was developed to study the relationships consumers perceive among different products, product benefits (e.g., low in calories), and their personal objectives (e.g., to be healthy). Unlike qualitative approaches to collecting such data, the APT approach enables us to quantify the relationships between the media channels and their perceived benefits, as well as between the situations and benefits in which we are interested. Furthermore, the questionnaire format of the APT enables us to collect data in an efficient (it is less time consuming than, say, laddering interviews) and relatively less costly manner, because experienced and trained interviewers are not needed. In comparison with more conventional scaling approaches, APT more clearly presents the questions about media channel-benefit relationships, uses a relatively simple response task (binary choices), and provides an insightful representation of the structure of interest. Thus, the APT approach is especially suitable for quantitative analyses of large-scale studies of media channel (or product) and benefit relationships.

To achieve our objective of investigating the effect of the usage situation on media channel consideration, we have adjusted the APT approach in several ways. We limit ourselves to only the relationship between media channels and perceived benefits. Whereas APT would include a second step to connect these

\footnotetext{
${ }^{2}$ This cutoff was based on budget constraints set by the firm with which we worked in this study. ${ }^{3}$ Respondents received questions that addressed additional research issues raised by our partner firm and that were not relevant for the objectives of our study.
} 
benefits to consumer objectives, we focus solely on the first layer of analysis. We also extend the APT approach to two other types of relationships: the connection between usage situations and media channel benefit requirements (e.g., Srivastava et al. 1981, 1984) and the effects of the usage situation on whether each media channel is considered for use to obtain product information.

The APT approach requires consumers to use a binary response to indicate, in preconstructed tables, which relationships they believe exist between different variables (e.g., products and benefits). In our study, we presented respondents with three tables: (1) benefits associated with each media channel (yes, no), (2) benefits a channel should have in a certain usage situation (yes, no), and (3) acceptability of each media channel in the specific usage situation. In a review of different measures of consideration, Brown and Wildt (1992) compare various measures designed to assess the concept of consideration and find only small differences for the semantic variations of the dependent variable of consideration (e.g., "consider acceptable for purchase," "would consider buying," "willing to buy"). We selected the formulation "consider acceptable for use in the specific usage situation" for our study because it is in line with both Brown and Wildt's (1992) findings and previous research on situational effects on consideration (e.g., Srivastava et al. 1984). We created three versions of the second and third table, each of which corresponds to one of the three product-related usage situations that we investigate. Respondents were randomly assigned to one of the three versions.

On the basis of three focus groups and discussions with industry experts, we identified 14 relevant media channels and eight media channel benefits that were most relevant in the context of food product information. Participants in the focus groups were consumers who were responsible for food purchases in their households. The industry experts included marketing managers from the food company with which we worked on this project and consultants working in the food industry. As part of the discussions during the focus groups and meetings with experts, we asked participants to list media channels that consumers could use to obtain food product information. Then, on the basis of this list of media channels, we asked them to discuss the specific benefits that each channel provided and any important differences that existed among them. This qualitative stage of our research 
provided us with the list of 14 main media channels that consumers might consider and eight main benefits related to these channels.

Of the 14 media channels in the survey, 3 were Internet-based channels: the manufacturer's Web site, a third-party Web site about cooking, and a food information Web site created by an independent agency. We also included 11 more traditional media channels, including television advertising, television programs, radio advertising, radio programs, magazine advertising, magazine articles, newspaper advertising, newspaper articles, in-store magazines, product labels, and educational brochures. ${ }^{4}$ The eight media channel benefits included in the study were whether a media channel was trustworthy ("trustworthy"), provided detailed information ("detailed"), took little time to use ("time saving"), was easy to use ("easy"), was tailored to the individual user ("personal"), was exciting and arousing ("stimulating"), was informative ("informative"), and was relaxing to use ("relaxing").

During the same focus group interviews and discussions with experts, we explored and selected product-related usage situations that were appropriate for the context of looking for information about food products. A common characteristic of these scenarios was that they described relatively specific usage situations to which consumers could easily relate. The following three hypothetical usage situations were identified: (1) a food scare in which an ingredient in one of the manufacturer's food products was contaminated, (2) a new product introduction in which the consumer is interested, and (3) a search for a recipe so the consumer can prepare a meal that includes one of the manufacturer's food products.

\subsubsection{SAMPLE CHARACTERISTICS}

The sociodemographics of the sample are diverse, with a slight emphasis on more highly educated men. Respondents' ages varied as follows: 16 to 24 years $14.1 \%, 25$ to 34 years $31.8 \%, 35$ to 49 years $38.2 \%, 50$ to 64 years $14.3 \%$, and 65

\footnotetext{
${ }^{4}$ In our analysis, we eliminated the media channels television advertising and radio advertising because they are relatively difficult for consumers to access on demand, as well as the most obtrusive. These two properties may constrain consumers who wish to obtain product information and therefore make these media channels less suitable for our analysis. The results did not change substantively after we eliminated these two media channels.
} 
years or older $1.5 \%$. The main observed education levels were as follows: university master's level 18.5\%, university bachelor's level $41.7 \%$, and professional education or other type of education $39.8 \%$. The gender distribution was $44.8 \%$ women and $55.2 \%$ men. Of the respondents, $21.8 \%$ lived alone, and the rest lived in households of more than one person; a total of $39.5 \%$ lived in households that included children under 17 years of age.

\subsubsection{ANALYSIS AND ECONOMETRIC MODEL}

To test Hypotheses 1, 2, and 4, we formulated a random coefficient binary logit model. Although prior research has modeled the impact of media communications on consumer behavior and its managerial implications (e.g., Lodish et al. 1995), surprisingly few models address consumers' perspectives on media channels. We propose a model that is largely consistent with the type of analysis conducted with APT data (e.g., Ter Hofstede et al. 1998) and in line with previous models of consideration developed by Andrews and Srinivasan (1995) and Bronnenberg and Vanhonacker (1996), who model the probability of considering an alternative as the probability that the alternative's utility exceeds the person's threshold of consideration.

In our analysis, we model the probability of consideration of a media channel $c$ by a person $i$ in usage situation $s(P(\operatorname{consider}(c, s, i)))$ as a function of the benefits of that channel that the person perceives, a usage situation-specific constant, and the benefits the person requires in that usage situation. To allow for heterogeneity in consumers' responses to usage situations and their valuations of the perceived benefits, we use a random coefficient specification (e.g., Train 2003). We express the probability of consideration as follows:

$$
P(\text { consider }(c, s, i))=P\left(B_{c s i}>T_{c s i}\right),
$$

where $B_{c s i}$ is consumer $i$ 's $(i \in I)$ latent evaluation of using a specific media channel $c(c \in C)$ in a specific usage situation $s(s \in S)$ to obtain product 
information, and $T_{c s i}$ is that consumer's latent threshold for consideration. We then express $B_{c s i}$ as follows:

$$
\begin{gathered}
B_{c s i}=\alpha_{c s i}+\boldsymbol{\beta}_{\mathbf{s i}} \mathbf{X}_{\mathrm{csi}}+\varepsilon_{c s i}, \\
\alpha_{c s i}=\alpha_{c}+\delta_{c s}+v_{i}, \text { and } \\
\boldsymbol{\beta}_{\mathbf{s i}}=\boldsymbol{\beta}+\gamma \mathbf{R}_{\mathbf{s i}}+\boldsymbol{\eta}_{\mathbf{i}}
\end{gathered}
$$

where $\alpha_{c s i}$ is the media channel intercept that is consumer- and usage situation-specific, $\mathbf{X}_{\mathbf{c s i}}$ is a vector of person $i$ 's perceived benefits of using channel $c$ in usage situation $s, \beta_{\mathbf{s i}}$ is a vector of the consumer- and usage situation-specific parameters for the effects of perceived channel benefits on channel evaluation, and $\varepsilon_{c s i}$ is an error component that captures, for example, measurement errors on the part of the researcher.

In addition, we express the media channel intercept $\alpha_{c s i}$ as a random coefficient with a media channel mean $\alpha_{c}$, a situation-specific media channel effect $\delta_{c s}$, and an error component $v_{i}$. We express the benefit parameter $\beta_{\mathbf{s i}}$ as a random coefficient vector that is a function of a vector of means $\beta$, a vector of a consumer's required benefits $\mathbf{R}_{\mathbf{s i}}$ with parameter $\gamma,{ }^{5}$ and a vector of error components $\eta_{\mathbf{i}}$. We assume that all errors in the random coefficient expressions are independently normal distributed but with different variances.

The consideration threshold therefore can be expressed as

$$
T_{c s i}=\alpha_{i}^{T}+\varepsilon_{c s i}^{T}
$$

where $\alpha_{i}^{T}$ is the consumer-specific threshold intercept, and $\varepsilon_{c s i}^{T}$ is the related error component. To obtain the random coefficient binary logit model, we

\footnotetext{
5 These estimates pick up the additional impact of a benefit on consideration when it is required versus when it is not required by the respondent. Therefore, even if the estimates $\beta$ of the main effects of different benefits are not significant, the $\gamma$ estimates may be significant and meaningful when the benefits are required.
} 
normalize $\alpha_{i}^{T}$ to 0 and assume that the error terms $\varepsilon_{c s i}$ and $\varepsilon_{c s i}^{T}$ are independently and identically Gumbel distributed.

To test the effect of the usage situation on consumers' media channel benefit requirements $(\mathrm{H} 3)$, we conduct a further analysis in which the dependent variables are consumers' responses regarding whether they believe each media channel should have different benefits in a given usage situation. We estimate a random coefficient binary logistic regression model with the dependent variable $\mathbf{R}_{\mathbf{s i}}$, the vector of person $i$ 's media channel benefit requirements in usage situation $s$, and the following independent variables: a situation-specific random coefficient intercept $\alpha_{s i}^{R}$ that is constant for the subject and for all benefits, a vector of dummy variables for each media channel benefit $\mathbf{X}_{\mathbf{m}}$ with the parameter $\boldsymbol{\eta}$, and the interaction of this vector with the vector of usage situation dummies $\mathbf{X}_{\mathbf{s}}$ with parameter $\boldsymbol{\theta}$. If these interactions are significant, they support the hypothesis that benefit requirements differ across usage situations (H3). We again assume that all error terms $\varepsilon_{s i}^{R}$ are independently and identically Gumbel distributed to obtain the binary logit model. The situation-specific intercept $\alpha_{s i}^{R}$ is expressed as a random coefficient with mean $\alpha_{s}^{R}$ and a normally distributed error component $v_{i}^{R}$ :

$$
\begin{gathered}
\mathbf{R}_{\mathbf{s i}}=\alpha_{s i}^{R}+\boldsymbol{\eta} \mathbf{X}_{\mathbf{m}}+\boldsymbol{\theta} \mathbf{X}_{\mathbf{s}} \mathbf{X}_{\mathbf{m}}+\boldsymbol{\varepsilon}_{\mathbf{s i}}^{\mathbf{R}} \\
\alpha_{s i}^{R}=\alpha_{s}^{R}+v_{i}^{R} .
\end{gathered}
$$

\subsection{Results}

\subsubsection{Media Channel Consideration Model}

We have hypothesized that a greater number of media channel benefits increases the probability that the media channel will be included in the consumer consideration set (H1), that different media channels may be considered in different usage situations (H2), and that consumers' media channel benefit requirements 
moderate the effect of these media channel benefits on media channel consideration by increasing their impact (H4). Testing these hypothesized relationships requires that we estimate the conceptual model (Equations 1, 2, and 3), which captures consumers' media channel consideration as a joint function of their perceptions of the media channel benefits, usage situation, and required benefits. We present these results in Table $2-1$.

The model results support $\mathrm{H} 1$; most media channel benefits have a significant and positive effect on media channel consideration. We observe significant $(p<.05)$ positive results for all media channel benefits except "trustworthy" and "informative." This outcome also reveals that consumers do not rely solely on channel-specific constants, as would be the case if the consumers used decision heuristics to avoid effort (Swait and Adamowicz 2001).

We also find significant differences in media channel intercepts depending on the usage situation (H2). In addition, the interaction of consumers' required media channel benefits with their perceived media channel benefits has a significant effect on consumer media channel consideration (H4), as we report in Table 2-1. Again, the results support the hypothesized relationships. We find significant $(p<$ .05) positive results for the media channel benefits "trustworthy," "easy," "stimulating," and "informative."

These findings suggest that even though the effects of perceived benefits and benefit requirements are significant in the model, they do not explain all the situational variation in consumers' media channel consideration; therefore, usage constants also are required. Furthermore, the results of the random coefficient estimates indicate significant coefficient heterogeneity across consumers' evaluations of the perceived media channel benefits, as well as across the media channel intercepts. 


\section{Table 2-1 Estimates of Random Coefficient Binary Logit Model ( $N=341)$}

\begin{tabular}{|c|c|c|c|}
\hline \multirow{2}{*}{$\begin{array}{l}\text { Intercept } \\
\text { Perceived benefits }\end{array}$} & \multirow[t]{2}{*}{ "-1.02(.08) } & & \\
\hline & & \multicolumn{2}{|c|}{ Interaction of required and perceived benefits } \\
\hline Trustworthy & $-.02(.15)$ & Trustworthy & $.43(.16)^{*}$ \\
\hline Detailed & $.32(.13)^{*}$ & Detailed & $.20(.14)$ \\
\hline Time saving & $.62(.10)^{*}$ & Time saving & $.07(.16)$ \\
\hline Easy & $.40(.08)^{*}$ & Easy & $.29(.10)^{*}$ \\
\hline Personal & $.77(.10)^{*}$ & Personal & $-.04(.22)$ \\
\hline Stimulating & $.29(.10)^{*}$ & Stimulating & $.54(.18)^{*}$ \\
\hline Informative & $-.01(.10)$ & Informative & $.96(.10)^{*}$ \\
\hline \multicolumn{2}{|l|}{ Media channel intercepts (mean) } & & \\
\hline Manufacturer Web site & $-.05(.15)$ & & \\
\hline Cooking Web site & $.62(.15)^{*}$ & & \\
\hline Independent nutrition Web site & $-.67(.16)^{*}$ & & \\
\hline Radio program & $-3.10(.30)^{*}$ & & \\
\hline Magazine advertisement & $-1.15(.19)^{*}$ & & \\
\hline Magazine article & $.62(.16)^{*}$ & & \\
\hline Newspaper advertisement & $-3.69(.32)^{*}$ & & \\
\hline Newspaper article & $-1.17(.16)^{*}$ & & \\
\hline Store magazine & $1.04(.16)^{*}$ & & \\
\hline Label & $-.05(.18)$ & & \\
\hline Brochure & $-.85(.15)^{*}$ & & \\
\hline \multicolumn{2}{|c|}{ Media channel intercepts (food scare-specific) } & \multicolumn{2}{|c|}{$\begin{array}{l}\text { Media channel intercepts (new product- } \\
\text { specific) }\end{array}$} \\
\hline Manufacturer Web site & $.11(.19)$ & Manufacturer Web site & $.13(.18)$ \\
\hline Cooking Web site & $-2.18(.22)^{*}$ & Cooking Web site & $-2.20(.20)^{*}$ \\
\hline $\begin{array}{l}\text { Independent nutrition Web } \\
\text { site }\end{array}$ & $1.27(.20)^{*}$ & $\begin{array}{l}\text { Independent nutrition Web } \\
\text { site }\end{array}$ & $-.46(.21)^{*}$ \\
\hline Radio program & $4.04(.32)^{*}$ & Radio program & $.41(.36)$ \\
\hline Magazine advertisement & $-.69(.25)^{*}$ & Magazine advertisement & $2.09(.23)^{*}$ \\
\hline Magazine article & $-1.31(.22)^{*}$ & Magazine article & $-1.43(.20)^{*}$ \\
\hline Newspaper advertisement & $3.60(.36)^{*}$ & Newspaper advertisement & $3.77(.35)^{*}$ \\
\hline Newspaper article & $2.69(.22)^{*}$ & Newspaper article & $-.34(.21)$ \\
\hline Store magazine & $-3.40(.24)^{*}$ & Store magazine & $-.55(.20)^{*}$ \\
\hline Label & $-1.11(.25)^{*}$ & Label & $-.24(.23)$ \\
\hline Brochure & $1.32(.20)^{*}$ & Brochure & $.54(.19)^{*}$ \\
\hline
\end{tabular}




\section{Table 2-1 continued}

\begin{tabular}{|c|c|c|c|}
\hline \multicolumn{4}{|c|}{ Estimates of Standard Deviations of Random Coefficients } \\
\hline \multicolumn{2}{|c|}{ Benefits (standard deviation) } & \multicolumn{2}{|c|}{ Media channel intercepts (standard deviation) } \\
\hline Trustworthy & $.78(.06)^{*}$ & Manufacturer Web site & $.07(.09)$ \\
\hline Detailed & $1.21(.05)^{*}$ & Cooking Web site & $.05(.10)$ \\
\hline Time saving & $1.10(.09)^{*}$ & Independent nutrition Web site & $.03(.10)$ \\
\hline Easy & $.23(.05)^{*}$ & Radio program & $.56(.13)^{*}$ \\
\hline Personal & $.32(.10)^{*}$ & Magazine advertisement & $1.56(.13)^{*}$ \\
\hline Stimulating & $1.01(.09)^{*}$ & Magazine article & $.97(.10)^{*}$ \\
\hline \multirow[t]{5}{*}{ Informative } & $.72(.04)^{*}$ & Newspaper advertisement & $2.66(.20)^{*}$ \\
\hline & & Newspaper article & $.03(.10)$ \\
\hline & & Store magazine & $.81(.11)^{*}$ \\
\hline & & Label & $2.16(.15)^{*}$ \\
\hline & & Brochure & $.58(.09)^{*}$ \\
\hline
\end{tabular}

* Significant difference at $\mathrm{p}<.05$.

Notes: The benefit "relaxing" and the situation "search for a recipe" serve as the base levels in the dummy coding of benefits and situations.

To test the hypothesized model further, we compare its fit with an alternative model that excludes the proposed interaction effects of benefit requirements (i.e., we drop the effect of $\mathbf{R}$ ). This model would be appropriate if consumers did not take into account their benefit requirements when they considered different media channels. The result, obtained through a log-likelihood ratio test (i.e., a $\chi^{2}$ test of $-2 \times$ difference in log-likelihood at 7 degrees of freedom), shows strong support for the model with interactions. The log-likelihood values of the models with and without interactions are -2275.3 and -2289.0 , respectively $(p<$ $.001)$.

To test H3, we estimate the model described by Equation 4 so that we can capture the dependence of consumers' media channel benefit requirements on the usage situation. We present the results in Table 2-2, which shows that consumers' required media channel benefits differ significantly according to the usage situation. In the case of a food scare, we observe significant $(p<.05)$ differences from the average for almost all required benefits except "easy" and "stimulating." 
Furthermore, we find significant $(p<.05)$ effects for a new product introduction for the benefits "trustworthy," "detailed," and "informative."

Table 2-2 Required Property Estimates of Random

Coefficient Binary Logit Model $(\mathrm{N}=341)$

\begin{tabular}{|c|c|c|c|}
\hline \multicolumn{2}{|l|}{$\begin{array}{l}\text { Situation-specific } \\
\text { intercepts }\end{array}$} & \multicolumn{2}{|c|}{ Estimates of standard deviations of random coefficients } \\
\hline Food scare & $-5.16(.61)^{*}$ & Food scare & $1.08(.09)^{*}$ \\
\hline New product & $-2.40(.19)^{*}$ & New product & $.55(.06)^{*}$ \\
\hline Recipe search & $-1.48(.14)^{*}$ & Recipe search & $.50(.05)^{*}$ \\
\hline \multicolumn{4}{|c|}{ Required benefits (mean) } \\
\hline Trustworthy & $1.85(.18)^{*}$ & & \\
\hline Detailed & $2.25(.18)^{*}$ & & \\
\hline Time saving & $.90(.17)^{*}$ & & \\
\hline Easy & $2.41(.18)^{*}$ & & \\
\hline Personal & $-.56(.22)^{*}$ & & \\
\hline Stimulating & $.66(.19)^{*}$ & & \\
\hline Informative & $1.87(.18)^{*}$ & & \\
\hline \multicolumn{2}{|c|}{ Required benefits (food scare) } & \multicolumn{2}{|c|}{ Required benefits (new product) } \\
\hline Trustworthy & $6.39(.69)^{*}$ & Trustworthy & $1.94(.31)^{*}$ \\
\hline Detailed & $4.72(.66)^{*}$ & Detailed & $1.03(.29)^{*}$ \\
\hline Time saving & $1.86(.65)^{*}$ & Time saving & $-.13(.29)$ \\
\hline Easy & $1.03(.64)$ & Easy & $.31(.29)$ \\
\hline Personal & $2.96(.72)^{*}$ & Personal & $.46(.36)$ \\
\hline Stimulating & $.06(.74)$ & Stimulating & $.49(.31)$ \\
\hline Informative & $5.34(.67)^{*}$ & Informative & $2.22(.30)^{*}$ \\
\hline
\end{tabular}

* Significant difference at $p<.05$.

To test for the collective effect of all situation-based interactions, we also compare the model that includes these interactions (H3) with one without interactions. At 14 degrees of freedom, the difference is significant in a $\chi^{2}$ test $(p<$ $.001)$, in support of our proposed model. 


\subsubsection{FURTHER ANALYSES}

Although our model of media channel consideration is well supported by academic literature and our empirical results, we also compare it with two rival models that have simpler structures. Specifically, we compare it with (1) a random coefficient model that does not include situational effects (i.e., $\alpha_{c s i}$ is fixed across usage situations and the effect of $\mathbf{R}$ is dropped) and (2) a null model with only a random coefficient intercept. To compare the models, we use log-likelihood ratio tests. The likelihood values are significantly $(p<.001)$ different from one another and from the proposed model structure.

We also evaluate the possibility that our results reflect common method effects. First, we consider the effects of the usage situation on consideration and requirements. In this case, there is no ground for a common method bias, because we manipulated the situations experimentally rather than according to responses by our participants (Podsakoff et al. 2003). Second, we evaluate the effects of the reported benefits and requirements on consideration, for which common method bias is a concern. Following Podsakoff et al. (2003), we classify our data collection as a "situation 7" case in which the predictor and criterion variables are not measured in different contexts and the source of the common method bias cannot be identified. The suggested response to such a case is twofold. First, in terms of data collection, we must separate the two types of responses as much as possible. We largely followed this requirement in our survey, because we presented respondents with separate response tables for perceived benefits, required benefits by situation, and media channel consideration by situation. Second, Lindell and Whitney (2001) suggest that the relative impact of the common method bias can be evaluated by calculating the lowest common correlation across all pairs of variables and subtracting it from the total correlation between each pair of variables. In our case, because we deal with binary responses, we calculate the corresponding $\Phi$ correlations. We find that the pattern of correlations is not significantly affected when we correct for the common correlation between all pairs. Therefore, we conclude that common method bias is not a severe problem in our analysis. 


\subsection{DISCUSSION}

\subsubsection{CONCLUSIONS}

The study presented in this chapter focuses on consumers' consideration of media channels. We develop a theoretical model to describe the effect of media channel benefits on consumers' media channel consideration and how this effect is influenced by the usage situation. Our findings not only support the hypothesized role of channel benefits in consumers' media channel consideration but also demonstrate that the usage situation is an influential contingency factor for consumers' media channel consideration. These results also indicate that the concept of consideration is useful for investigating consumers' media channel use in the field of manufacturer-to-consumer communications. Furthermore, situational effects prove to be important for analyzing media channel considerations.

Specifically, we find support for the hypothesis that a greater number of media channel benefits increases the probability that the media channel will be included in the consumer's consideration set (H1). The results also provide support for the moderating effect of the usage situation (H2) and consumers' benefit requirements (H4) through the significant interaction effect of perceived and required media channel benefits. Finally, we investigate the role of the usage situation as a driver of consumers' required media channel benefits (H3). The results reveal that some benefits are required only in certain situations. For example, in the case of a food scare, "easy" and "stimulating" benefits are not important to consumers, whereas in the case of a new product introduction, benefits such as "time saving," "easy," "personal," and "stimulating" are unimportant. This result illustrates that consumers' required benefits depend on the usage situation.

\subsubsection{THEORETICAL AND MANAGERIAL IMPLICATIONS}

The main implications of our findings for theory are twofold. First, we find support for the idea that we can transfer the notion of consumers engaging in relatively active consideration set formation from product evaluation to media channel evaluation, at least in the usage situations that we investigate. This finding provides opportunities for further research on utility-based models of media channel 
consideration similar to those used in the product choice literature (Roberts and Lattin 1997).

Second, our results provide empirical support for the SIU approach, particularly the suggestion by Srivastava et al. (1981) that product use depends on the match between product benefits and situation characteristics. Although this mechanism has been described previously, little empirical evidence exists to support the moderating role of situation requirements on the effect of benefit consideration. Our results show that this moderating effect occurs and that the SIU approach generalizes.

A main managerial implication of our study is that marketing managers should investigate consumers' consideration sets for media channels. In some usage situations, consumers may prefer a media channel that saves them time. In others, they may focus on information quality. For example, independent Web sites are regarded as very trustworthy and therefore represent a good media channel to provide consumers with information in case of a food scare but not one to provide them with recipe suggestions (where ease of use is more important).

\subsubsection{LIMITATIONS AND DIRECTIONS FOR FURTHER RESEARCH}

In this study, we include media channels and benefits on the basis of qualitative research and experts' judgments. During the interviews and discussions with industry experts, we encouraged respondents to add additional media channels and/or benefits. This approach provides a relatively close fit with the respondents' vocabulary and considerations in the context in which we conducted our research (food products). However, other channels and benefits could be considered, such as communities, chat rooms, or discussion forums (e.g., Ratchford, Talukdar, and Lee 2001; Zinkhan et al. 2003). Although the investigated benefits are largely consistent with previous research, our approach required us to rephrase or omit certain characteristics. For example, perceived availability may be a combination of ease of access and the specific information obtained. Similarly, the nonintrusive benefit was captured, in part, by the benefits trustworthy, detailed, personal, and informative. 
Additional research might investigate the interaction of information and purchase channels. One possible avenue might be to explore a situation in which consumers use one channel to obtain product information and a different channel for purchase (e.g., an Internet context). Thus, we hope that this study stimulates more marketing research on the role of situations in consumer media channel usage. 


\section{Chapter 3}

\section{SITUATION-BASED SHIFTS IN CONSUMER BENEFIT SALIENCE: THE JOINT ROLE OF AFFECT AND COGNITION}

This study addresses the process by which benefits become salient in consumers' minds across various usage situations. We explore two routes (cognitive and affective) by which the situation jointly influences benefit salience, in terms of both benefit importance and the number of salient benefits. We find support for the proposed dual route structure of our model, indicating that individuals' relative benefit importance ratings shift across usage situations both directly and indirectly through consumers' positive affective state. In addition, we find that more positive affect increases the number of salient benefits, providing insight as to why the number of salient benefits may vary across usage situations. 


\subsection{INTRODUCTION}

Advanced information and communication technologies now allow firms to provide consumers with anytime, anywhere access to many of their communications and services (e.g., product information, access to ordering, after-sales services). This type of highly flexible interaction with consumers places new requirements on firms, because they need to design their interfaces and services to meet variations in consumer demands across a wide variety of usage situations (Seybold 2001). In particular, the benefits that consumers require in products and channels may vary strongly across usage situations (Gutman 1982; Srivastava, Alpert, and Shocker 1984; Wendel and Dellaert 2005).

Although previous research emphasizes that situational differences are particularly important in understanding consumer behavior (Belk 1974, 1975; Gutman 1982; Lutz and Kakkar 1975), few studies have addressed the question of how these benefits are made salient in consumers' minds. It has been suggested that benefit salience is rooted in a selection process, whereby some benefits are cognitively more accessible in memory to the consumer in a particular usage situation because of their strong associations with past experiences (Ratneshwar et al. 1997). This cognitive structure implies that consumers process decision information in a selective manner, depending on the thoughts activated in a specific situation (Bruner 1957 in Ratneshwar et al. 1997). The role of affective states in explaining variation in consumer benefit salience also has been suggested as an important area for research (Lutz and Kakkar 1975). Although this alternative approach is intuitively plausible, it remains a relatively unexplored research domain.

The objective of this chapter is to combine these two perspectives and jointly investigate the affective and cognitive routes by which situational differences in benefit salience may arise. We identify the importance and number of salient benefits as two important dependent variables that can be influenced by the situation, through either a cognitive or an affective path, and develop a model that simultaneously includes the two (possibly) complementary routes. We test hypotheses based on the proposed structure in the context of consumer information 
Web sites about food. On the basis of these results, we discuss theoretical and managerial contributions and conclude with some limitations of our study, as well as future research suggestions.

\subsection{Situation VARIATION AND BENEFit SALIENCE}

In our conceptualization of the effect of situation on benefit salience, we follow the definition of situation proposed by Belk (1974), which has been used extensively in previous research and supports the idea that situation influences consumer behavior (Belk 1975; Warlop and Ratneshwar 1993). According to this definition, a situation consists of five dimensions - physical surrounding, social surrounding, temporal perspective, task definition, and antecedent state - of which we use a subset in our empirical analysis. The substitution-in-use approach (Srivastava et al. 1984; Srivastava, Leone, and Shocker 1981) extends earlier work on situational effects on consumer behavior by proposing that the benefits that consumers require a product to have vary across usage situations. Srivastava et al. (1984) also argue that consumers look specifically for the benefits that products provide rather than for the products themselves and emphasize the impact of the environment surrounding the product and the consumer. In this sense, the benefits consumers look for vary across usage situations, which therefore influence their preferences for specific products. Warlop and Ratneshwar (1993) suggest that when examining the impact of the situation on consumer decision making (e.g., preference, consideration), it is important to understand the underlying cognitive processes (e.g., benefits sought in the specific situation) consumers use in their problem-solving process. These authors illustrate that the benefits sought may differ among usage situations (familiar versus unfamiliar) and therefore that variations in benefits can offer a possible explanation for the observed effects of usage context. Also, Ratneshwar et al. (1997) argue that product benefits can be more or less salient according to the context of a particular usage situation (situational benefit salience).

In the current study, we integrate this cognitive approach that explains the impact of situation on consumer benefit salience with work emphasizing the 
importance of analyzing the situation in terms of its psychological representation by consumers (Lutz and Kakkar 1975). To do so, we represent consumers' internal state variables (affective states) in our model not just as part of the situation itself but rather separately, as additional components of consumers' responses to the situation. Figure 3-1 graphically summarizes this conceptualization and our hypotheses.

\section{Figure 3-1 Conceptual Model of Situational Impact on Benefit Salience}

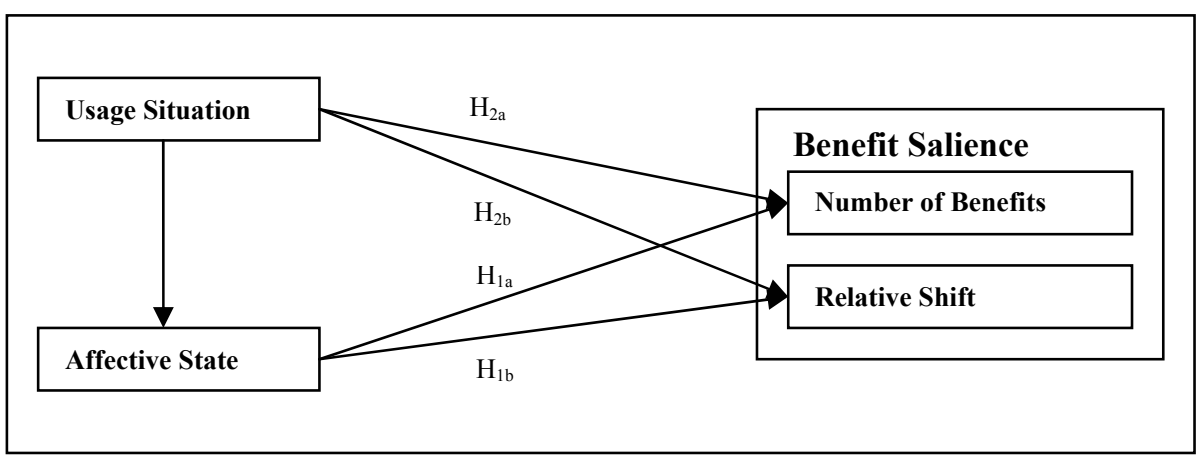

\subsubsection{AFFECTIVE RoUTE}

The importance of the impact of situation on consumers' affective responses (e.g., pleasure and arousal) has long been recognized (Gardner 1985; Lutz and Kakkar 1975). Since its origins in the field of environmental psychology, the influence of various stimuli on consumers' affective states has received considerable empirical support. For instance, extant literature focuses on consumers' emotional responses to various consumption experiences (Mano and Oliver 1993; Westbrook 1987), the impact of retail shopping environments (atmospherics) on consumers' emotional states (Donovan and Rossiter 1982), and consumers' emotional responses to various types of advertising (Zinkhan and Fornell 1985).

Two key dimensions of consumer affective response are pleasure and arousal (Lutz and Kakkar 1975; Russell and Mehrabian 1977; Zinkhan and Fornell 1985). In particular, work on semantic differentials indicates that these dimensions 
represent two of the most important consumer emotional states (Osgood, Suci, and Tannenbaum 1957; Smith and Swinyard 1982) for explaining affective responses to a wide variety of stimuli (Mehrabian and Russell 1977). Therefore, in our analysis of consumers' affective responses to situations, we focus on these two key dimensions. We define pleasure as the component of the affective response that expresses feelings such as happiness, contentment, and satisfaction (Lutz and Kakkar 1975) and reflects whether a person feels good in an environment (Baker, Levy, and Grewal 1992). Arousal is defined as the component of affective response that expresses how excited and stimulated a person feels (Baker et al. 1992; Lutz and Kakkar 1975).

In line with Watson and Tellegen (1985), we acknowledge a more positive affective response if consumers' pleasure, arousal, or both increase. To manipulate affective responses in our empirical analysis, we adopt the approach taken in many studies that manipulate positive affect by inducing pleasure/positive mood (e.g., giving a small gift such as candy) (Kahn and Isen 1993; Meloy 2000). However, we also recognize that people who are highly aroused may be experiencing positive affect (Watson and Tellegen 1985) and therefore control for arousal and include both pleasure and arousal in our model estimation.

Information-processing literature in marketing examines a wide number of variables, including filtering, information storage, retrieval, attribute importance, consumer evaluation, and intentions, among others (Hong and Wyer 1990; MacKenzie 1986). The premise that emotional states have an influential impact on consumer decision making has found conclusive support among researchers (Bagozzi, Gopinath, and Nyer 1999; Mano 1992). For instance, the importance of affective states (e.g., pleasure) has received considerable attention with regard to consumers' information processing, including the encoding and retrieval of information and the diverse evaluation strategies consumers might use in processing information (Bagozzi et al. 1999; Sanbonmatsu and Kardes 1988). In retail settings, the significance of emotional responses has been emphasized to predict consumer behavior more precisely (Baker et al. 1992; Donovan and Rossiter 1982). Baker et al. (1992) explore the impact of emotional states on consumers' intended shopping 
behavior (e.g., time spent in the store, intention to return) and find support for this effect.

Moreover, various researchers have argued that positive affect amplifies consumers' decision making and encourages approach behavior (Isen 2001; Menon and Kahn 2002). Isen (2001), on the basis of a review of the literature about the influence of positive affect on decision making, states that positive affect increases consumers' problem solving and that consumers integrate more information into their decision making. Furthermore, "positive affect facilitates creativity, cognitive flexibility, innovative responding, and openness to information" (Isen 2001, 76). Also, Kahn and Isen (1993) find that consumers who experience positive affect seek more variety in their product choices, just as people who experience positive affect generally enhance their elaboration and thinking. Therefore, people in a positive affective state appear to experience the task as an enjoyment in itself and consequently are stimulated to process more information (Mano 1997). We hypothesize that respondents who experience higher positive affect are more open and willing to process information and in turn experience more salient benefits.

H1a: Usage situations associated with greater positive affect lead to a greater number of salient benefits.

Extending the theoretical explanation for $\mathrm{H} 1 \mathrm{a}$, we propose a further underlying process that links consumers' affective states and consumer decision making (Isen and Geva 1987). According to Isen and Geva (1987), who induce positive affect and ask respondents to participate in a gamble to measure their risk preferences, people who feel good (i.e. positive affect) wish to maintain this state and are less willing to take risks. Instead, they behave very conservatively (i.e., focus on the loss) to maintain their happy mood. This outcome falls in line with results reported by Meloy (2000), who investigates the impact of positive mood on consumers' product information processing and finds that consumers in a more positive mood process information that is more congruent with their positive state to sustain their mood. We anticipate that a comparable process takes place with regard to the effects of situation-induced mood on benefit salience. That is, consumers who 
experience positive affect wish to maintain this affective state, and therefore, benefits that are more pleasure-oriented become more salient.

H1b: Usage situations associated with greater positive affect lead to the greater salience of pleasure-oriented benefits.

\subsubsection{COGNITIVE Route}

Other researchers have addressed the role that cognitive processes play in linking usage situations and consumer decision making (Ratneshwar and Shocker 1991; Sinha 1994; Srivastava 1981; Warlop and Ratneshwar 1993). For instance, Srivastava (1981) argues that it is unlikely people will react inherently differently to each consumption occasion. Instead, consumers rely on prior learning and their experiences when faced with a specific situation in which they need to retrieve information. This line of reasoning is based on the premise that consumers have limited information-processing capacities (Bettman 1979) and therefore group and store prior learning and experiences in memory according to some categorization. The notion that people have limited information-processing capabilities, including memory restrictions, has been well documented (e.g., Newell and Simon 1972).

Consistent with this notion, we expect that, because of consumers' limited working memory, only a subset of benefits will be made salient (accessed from stored knowledge because they are triggered by the situational context). We also expect that when we control for the variations in consumers' affective states, the size of this subset will be independent of the usage situation and relatively stable in terms of the number of benefits (i.e., will have no effect on the number of salient benefits) across usage situations.

H2a: The number of salient benefits does not differ across usage situations, when controlling for a consumer's affective state.

However, we expect the relative salience of different benefits to depend on the situation the consumer faces. For example, service response time may be a benefit that is especially salient for consumers who are pressured for time. In 
contrast, consumers who are exploring new products might not consider service response time a salient benefit but instead focus on other benefits such as entertainment value.

Warlop and Ratneshwar (1993) build on similar ideas and explore the role of usage situation (familiar versus unfamiliar) on consumers' memory-based processes. The results illustrate that consumers in familiar situations rarely mention product attributes or benefits (i.e., fewer constructive thought processes) but instead "directly retrieve solutions appropriate to the problem defined by the usage context" (378). They suggest "retrieval based on event scripts cued by the situation" and "retrieval based on episodic memory of similar situations" as two possible processes by which consumers might recall a possible solution directly in a familiar situation. Furthermore, Ratneshwar and Shocker (1991) propose that the usage context might activate a certain schemata that helps consumers retrieve those benefits that are essential in the situation. In turn, consumers call up products from memory that are associated with these benefits. More recently, Weber and Johnson (2006) adopted a similar reasoning to highlight the importance of memory in consumers' preference construction. Such queries may be either unconscious (typically automatic) or conscious in nature.

We expect that a similar process occurs in the context of our study. That is, there is a direct route from the situation to the benefits made salient in consumers' minds; this effect can be explained through a memory-based process. If a situation may be recalled easily from memory (whether consciously or unconsciously) based on prior knowledge or experience, consumers directly retrieve solutions (i.e., salient benefits) to the choice problem. Consider as examples the following situations: an Internet user finds herself under considerable time pressure as she searches for recipe information. In this situation, the user might call up prior experiences and thereby bring to mind certain benefits that are important in this specific situation (e.g., retrieving information fast). In contrast, a person who is flipping through a recipe book, as a source of leisure reading, likely activates and experiences a very different set of benefits (e.g., entertainment value). These examples illustrate that the situation can assist consumers' decision making by triggering certain experiences, 
based on cognitive processes that are linked to the salience of the different benefits demanded by the situation.

H2b: The relative salience of different benefits shifts across usage situations, even when controlling for a consumer's affective state.

\subsection{MeThOD AND DATA}

We test the proposed hypotheses empirically in the context of consumers' information search for food products over the Internet. The Internet particularly emphasizes the importance of anytime, anywhere access for many consumer-firm relationships, which raises the question of how firms can meet these varying needs across individual consumers. For example, searching for information on a food manufacturer's Web site about a product that has just been introduced on the market is likely to lead a person to look for very different benefits (e.g., informational content, quality of the system) than would looking for information on that same Web site after the announcement of food scare. In the latter situation, the consumer might most value a Web site that provides relevant, up-to-date information, whereas in the former, the consumer might value a more entertaining Web site with interactive features. The interactive nature of the Internet also raises important questions about how Web sites should be designed to meet consumers' demands (Stewart and Pavlou 2002). The vast increase in consumers' concerns about healthrelated factors (e.g., dieting, nutrition, self-medication) (Moorman and Matulich 1993) further emphasizes the relevance of this application.

\subsubsection{PARTICIPANTS AND DESIGN}

We collected data through an online survey run with two university panels. Participants in these panels are largely volunteers but are eligible to win a gift voucher for taking part in the research. The online survey for this study was completed by 281 respondents, though responses from 5 participants contained outliers and were eliminated from further analysis. Therefore, we possess a sample 
of 276 subjects, $22.5 \%$ of whom are men. The mean of the age of the respondents is 24.4 years.

We adopt a $2 \times 2$ between-subject experimental design to vary the situation and assign respondents randomly to one of four conditions that represent different hypothetical online information search situations. Anchored in the work of Belk (1975), we focus on time and social factors as two situational characteristics for manipulation. To create the two time conditions, we alter the time that respondents had available in the hypothetical task. In the high time pressure condition, respondents were told that they would have to search for a recipe on the Internet to prepare a dinner for tomorrow night, whereas in the low time pressure situation, the dinner was scheduled to take place in two weeks. To create the two social conditions, we manipulated the social context in which respondents had to search for a recipe on the Internet. Respondents in the high social pressure situation recently made a new female friend that they wanted to impress, and this friend valued a healthy, low calorie dinner. In the low social pressure situation, respondents were told that a dinner for a housemate had to be prepared (see Appendix 3A for an overview of the scenarios). After respondents had been exposed to the scenarios, we assessed their ratings of perceived affective states (i.e., pleasure and arousal) and salience measures.

The manipulation checks employ seven-point Likert-type scales $(1=$ strongly disagree, $7=$ strongly agree). The manipulation check for social pressure consists of four items (Houston and Walker 1996), slightly adapted for the context of our study. After reading the description of the situation, subjects responded to the following items: (1) I find it necessary to look for information, (2) the person expects to receive the right menu from me, (3) the person coming for dinner would be disappointed if I had forgotten to look for the information, and (4) I absolutely have to look for the information. We compare the average of these items across the high and low social pressure groups and find a significant difference between the means of the low social pressure group $(M=3.51, n=130)$ and high pressure group $(M=4.00, n=146)(t=3.3, p=<.001)$.

To measure the perceived level of time pressure, respondents answered the following questions (after being exposed to the situation): (1) I find myself pressed 
for time, (2) I am in hurry, (3) I must finish looking for information fast since I have other things to do, and (4) I have more than enough time to look for the necessary information (Putrevu and Ratchford 1997). The averages of these items in the low time pressure group $(M=2.16, n=135)$ and the high time pressure group $(M=3.04$, $n=141)$ are significantly different $(t=6.79, p=<.001)$. Therefore, we are confident that our manipulations worked.

Finally, we performed a realism check to test whether consumers found the situation realistic. We selected a seven-point Likert-type scale $(1=$ strongly disagree, 7 = strongly agree) (Dabholkar and Bagozzi 2002) and asked respondents to rate the following two items: (1) the situation described was realistic and (2) I had no difficulty to imagine myself in the situation. The results showed that respondents had no difficulties imagining themselves in the given situation, with ratings of $M=$ 4.68 and $M=5.08$ for the two items, respectively.

\subsubsection{Measurement AfFective States}

We capture two aspects of respondents' affective states: pleasure and arousal. To measure responses to these two dimensions, we use seven-point bipolar adjectival scales (Lutz and Kakkar 1975; Mehrabian and Russell 1974). Specifically, we measure pleasure by asking respondents to rate the following items: unhappy/happy, melancholic/contented, annoyed/pleased, unsatisfied/satisfied, despairing/hopeful, and bored/relaxed. Respondents rated their arousal according to the following items: sluggish/frenzied, calm/excited, relaxed/stimulated, unaroused/aroused, dull/jittery, and sleepy/wide awake.

\subsubsection{MEASUREMENT BenEFITS}

In total, we define 13 benefits: relevance, understandability, reliability, adequacy, scope, usefulness, usability, speed, entertainment, navigation, interactivity, hyperlinks, and decisional control. Taken together, these benefits represent the main themes in current management information system and marketing literature (Mathwick and Rigdon 2004; McKinney, Yoon, and Zahedi 2002; Wolfinbarger and Gilly 2003). Table 3-1 provides an overview of the benefits and sources of their scales. We adapt the benefits slightly to the context of our study and 
measure them using a seven-point Likert-type scale $(1=$ strongly disagree, $7=$ strongly agree). Appendix 3B provides an overview of the scale items.

To measure benefit salience, we asked respondents to indicate on a sevenpoint Likert-type scale how important they found the benefits to be in the particular experimental usage situation (van Kenhove, de Wulf, and van Waterschoot 1999). We assessed the number of benefits made salient by determining how often respondents indicated a score of six or higher for each benefit (composite score) and adding those scores. 


\section{Table 3-1 Benefits}

\begin{tabular}{|c|c|c|}
\hline Dimension & Description & Source \\
\hline Relevance & $\begin{array}{l}\text { The extent to which the user perceives the information } \\
\text { to be relevant and applicable to accomplish a certain } \\
\text { task }\end{array}$ & McKinney et al. (2002) \\
\hline Understandability & $\begin{array}{l}\text { The extent to which the user perceives the information } \\
\text { to be clear in meaning, easy to understand, and easy to } \\
\text { use }\end{array}$ & McKinney et al. (2002) \\
\hline Reliability & $\begin{array}{l}\text { The extent to which the user perceives the information } \\
\text { to be accurate, dependable, and consistent }\end{array}$ & McKinney et al. (2002) \\
\hline Adequacy & $\begin{array}{l}\text { The extent to which the user perceives the information } \\
\text { to be sufficient and complete }\end{array}$ & McKinney et al. (2002) \\
\hline Scope & $\begin{array}{l}\text { The extent to which the user perceives the information } \\
\text { to cover a wide range and variety of topics }\end{array}$ & McKinney et al. (2002) \\
\hline Usefulness & $\begin{array}{l}\text { The extent to which the user perceives the information } \\
\text { to be informative and valuable }\end{array}$ & McKinney et al. (2002) \\
\hline Usability & $\begin{array}{l}\text { The extent to which the user perceives the Web site as } \\
\text { visually appealing, easy to use, and user-friendly }\end{array}$ & McKinney et al. (2002) \\
\hline Speed & $\begin{array}{l}\text { The extent to which the user perceives the Web site as } \\
\text { fast }\end{array}$ & Muylle et al. (2004) \\
\hline $\begin{array}{l}\text { Entertainment } \\
\text { Value }\end{array}$ & $\begin{array}{l}\text { The extent to which the user perceives the Web site to } \\
\text { offer immediate pleasure for its own sake }\end{array}$ & Mathwick et al. (2001) \\
\hline Navigation & $\begin{array}{l}\text { The extent to which the user perceives the Web site to } \\
\text { be easy to navigate }\end{array}$ & McKinney et al. (2002) \\
\hline Interactivity & $\begin{array}{l}\text { The extent to which the user perceives the Web site to } \\
\text { provide tailored/personalized information to meet } \\
\text { specific needs }\end{array}$ & Loiacono et al. (2002) \\
\hline Hyperlinks & $\begin{array}{l}\text { The extent to which the user perceives the Web site to } \\
\text { offer an adequate number and clear links }\end{array}$ & McKinney et al. (2002) \\
\hline $\begin{array}{l}\text { Decisional } \\
\text { Control }\end{array}$ & $\begin{array}{l}\text { The extent to which the user perceives that the Web } \\
\text { site supports decision making and flexibility }\end{array}$ & Mathwick et al. (2004) \\
\hline
\end{tabular}




\subsection{RESULTS}

\subsubsection{CONFIRMATORY FACTOR ANALYSIS}

We conducted two confirmatory factor analyses to purify our scales. First, we test for the reliability of the pleasure and arousal constructs. We deleted the following items because of their low factor loadings and/or high modification indices: bored/relaxed, unsatisfied/satisfied, calm/excited, sleepy/awake, and sluggish/frenzied. The subsequent results provide a good model fit $\left(\chi^{2}(13)=30.15\right.$, $p<.005$; comparative fit index $[\mathrm{CFI}]=.98$, nonnormed fit index $[\mathrm{NNFI}]=$ TuckerLewis index $[\mathrm{TLI}]=.97$, root mean square error of approximation $[\mathrm{RMSEA}]=.069$, and adjusted goodness-of-fit index $[\mathrm{AGFI}]=.93$ with a standard root mean square residual [SRMSR] of .042). All factor loadings are significant ( $t$-values greater than 6.79), and all completely standardized loadings are greater than .57 with an average of .77. These findings support the convergent validity of our measures. Cronbach's alphas are .88 and .68 for pleasure and arousal, respectively. To verify the discriminant validity, we followed the approach by Fornell and Larcker (1981), which states that the average variance extracted (AVE) of a latent construct must be greater than the squared correlations with other latent constructs. The estimates of the AVE are .82 and .61 for pleasure and arousal, respectively, and exceed the squared correlation of these constructs. Consequently, we average the appropriate scale items to obtain a composite score for pleasure and arousal.

We conducted a second confirmatory factor analysis to test the reliability of the 13 benefits and deleted 7 items because of their low factor loadings and/or high modification indices across constructs (see Appendix 3B for an overview of all scale items). This deletion provides a good model fit $\left(\chi^{2}(599)=1515.08, p<.001, \mathrm{CFI}=\right.$ $.96, \mathrm{NNFI}=\mathrm{TLI}=.95, \mathrm{RMSEA}=.075$, and AGFI $=.72$ with $\mathrm{SRMSR}=.048)$. All factor loadings are significant (t-values greater than 11.80), and all completely standardized loadings are greater than .69, with an average of .86. These findings support the convergent validity of the measures. Cronbach's alphas of all factors range from .79 to .90 (Appendix 3B). The estimates of the AVE range from .75 to .9 and are larger than the squared correlations with the other constructs, which 
provides evidence of discriminant validity. We therefore average the appropriate scale items to obtain a composite score for each benefit.

\subsubsection{HYPOTHESIS TESTING}

We performed two analyses to test the proposed conceptual model. First, we analyzed the effect of positive affect and situation on the number of salient benefits (H1a and H2a). Second, we tested the influence of positive affect (i.e., pleasure) and situation (i.e., time pressure and social pressure) on benefit salience (H1b and $\mathrm{H} 2 \mathrm{~b})$.

For expositional clarity, we first express the formal model specification for benefit salience in Equation 1, which is more elaborate than the specification for the effect of situation on the number of benefits:

$$
\begin{aligned}
\mathbf{B}_{\mathbf{j s}} & =\boldsymbol{\alpha}+\boldsymbol{\beta}_{\mathbf{P}} P_{j s}+\boldsymbol{\beta}_{\mathbf{A}} A_{j s}+\boldsymbol{\beta}_{\mathbf{S}} \mathbf{S}+\boldsymbol{\varepsilon}_{\mathbf{j s}}, \\
P_{j s} & =\alpha_{P}+\boldsymbol{\beta}_{\mathbf{P S}} \mathbf{S}+\varepsilon_{P j s}, \\
A_{j s} & =\alpha_{A}+\boldsymbol{\beta}_{\mathbf{A S}} \mathbf{S}+\varepsilon_{A j s}
\end{aligned}
$$

where $\mathbf{B}_{\mathbf{j}}$ is a vector of benefit salience for individual $j$ in situation $s, P_{j s}$ is individual $j$ 's pleasure in situation $s, A_{j s}$, is individual $j$ 's arousal in situation $s$, and $\mathbf{S}$ is a vector of situation factors (time pressure and social pressure) that determine situation $s$. The parameters $\alpha, \alpha_{P}$, and $\alpha_{A}$ are (a vector of) intercepts in the benefit salience, pleasure, and arousal equations, respectively. $\beta_{\mathrm{P}}, \beta_{\mathrm{A}}$, and $\beta_{\mathrm{S}}$ are vectors of the effects of pleasure, arousal, and the situation factors on benefit salience; $\beta_{\mathbf{P S}}$ is a vector of effects of situation factors on pleasure; and $\beta_{\mathrm{AS}}$ is a vector of the effects of situation factors on arousal. Finally, $\varepsilon_{\mathrm{js}}, \varepsilon_{\mathrm{Pjs}}$, and $\varepsilon_{\mathrm{Ajs}}$ are (a vector of) error terms in the benefit salience, pleasure, and arousal equations, respectively. These error terms are assumed to be normally distributed. To allow for simultaneous estimation of the different relationships in the model and correct for endogeneity in the disturbance terms of the corresponding equations, we use the three-stage least squares (3SLS) approach in our estimation. 
The expression for the number of salient benefits is expressed analogously, but the benefit salience vector $\mathbf{B}_{\mathbf{j}}$ is replaced by a single indicator $N_{j s}$ of the number of salient benefits for individual $j$ in situation $s$.

\subsubsection{RESULTS}

As anticipated, positive affect increases the number of salient benefits, in support of $\mathrm{H} 1 \mathrm{a}^{6}$ (Table $\left.3-2\right)$. This effect is caused by both pleasure $(\beta=3.08, p<$ $.01)$ and arousal $(\beta=2.29, p<.01) .^{7}$ We also test for the effect of situation on positive affect and find that social pressure increases both pleasure $(\beta=.29, p<.05)$ and arousal $(\beta=.27, p<.05)$. However, we do not observe an effect for time pressure on pleasure and arousal.

As expected, the results of the analysis of the situational effect on the number of salient benefits show no effect of time pressure. Surprisingly however, social pressure decreases the number of salient benefits $(\beta=-1.44, p<.01)$, even when we control for the effects of affective state. As a result, we find partial support for $\mathrm{H} 2 \mathrm{a}$.

\section{Table 3-2 3SLS Estimates of Number of Salient Benefits}

\begin{tabular}{lccc}
\hline \hline & \multicolumn{3}{c}{ Dependent Variables } \\
\hline & Pleasure & Arousal & Number of Salient Benefits \\
\hline Time pressure & & & \\
Social pressure & $.29^{*}$ & $.27^{*}$ & $-1.44^{* *}$ \\
Pleasure & & & $3.08^{* *}$ \\
Arousal & & $2.29^{* *}$ \\
\hline \hline Notes: Only significant effects are reported. & & \\
$* \quad p<.05$. & & \\
$* * \quad p<.01$. & & \\
& &
\end{tabular}

\footnotetext{
${ }^{6}$ Arousal also increases the number of salient benefits, which suggests positive affect might be triggered by arousal.

${ }^{7}$ We also performed a more rigid analysis, in which we assess the number of salient benefits by determining how often respondents indicate a score of five and higher. The results $(\beta=2.45, p<.01)$ support the hypothesized relationship.
} 
Next, we test the effect of situation on benefit salience (Table 3-3). The results illustrate that social pressure has a significant negative effect on adequacy $(\beta$ $=-.25, p<.05)$, scope $(\beta=-.43, p<.05)$, usefulness $(\beta=-.24, p<.05)$, speed $(\beta=$ $.35, p<.05)$, entertainment $(\beta=-.42, p<.05)$, navigation $(\beta=-.33, p<.05)$, and decisional control $(\beta=-.63, p<.01)$. Furthermore, time pressure has a significant negative effect on entertainment $(\beta=-.40, p<.05)$. Given our interest in the relative shift of individual respondents' benefit salience, we next conduct a Wald test and restrict the shift within both manipulation conditions to be constant. The Wald test results are significant $\left(\chi^{2}=34.94, d f=22, p=.05\right)$ and provide further evidence that the relative importance of benefits shifts across the situations. Further exploration shows that this effect is driven by time pressure more than by social pressure. Consequently, we find support for $\mathrm{H} 2 \mathrm{~b}$. Moreover, the results illustrate that positive affect (i.e., pleasure) has the strongest influence on the benefit entertainment, in support of H1b. To examine whether the differences between entertainment and the remaining benefit are significant, we perform several Wald tests and find significant differences at the .05 level between entertainment and all other benefits except interactivity. 


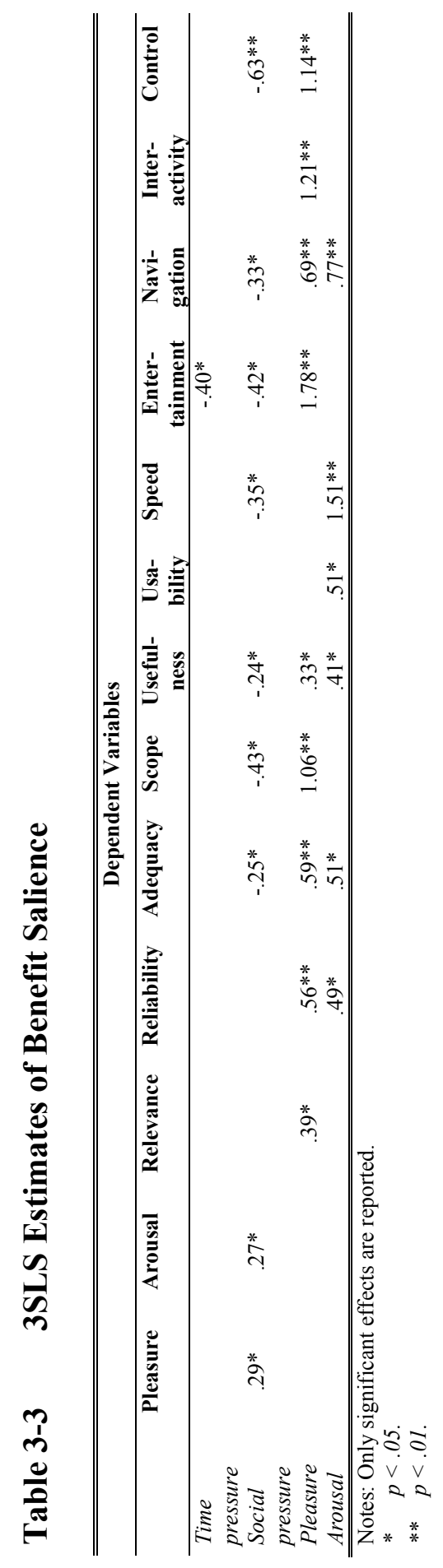




\subsection{Discussion}

\subsubsection{CONCLUSIONS}

For many years, researchers have attempted to describe the role of situation for marketing (Belk 1975). Because situation and its influences are such complex phenomena, it is no surprise that marketing researchers have made relatively little empirical progress in this area. We demonstrate the importance of situation on the number of benefits made salient to consumers as well as on the relative salience of these different benefits. Furthermore, we illustrate that the mechanism involved in this process is multifaceted. Overall, our results provide support for the conceptual model, including strong evidence that positive affect (pleasure) has a direct effect on the number of salient benefits. The decrease in the number of salient benefits for consumers who experience social pressure is an unforeseen finding of our study, but we suggest this outcome might emerge because the social pressure condition we use is not as perceptible in consumers' working memory as is the time pressure condition. Time pressure might be a situational characteristic that people can relate to more easily and therefore call upon more rapidly to link the benefits to the demands of the situation. In contrast, the high social pressure situation might not trigger an apparent set of benefits, which would make fewer benefits salient.

The situations that we examine seem to trigger salience for some benefits but not others, and those which are salient shift across the manipulation conditions, as hypothesized. We also note that consumers who experience positive affect find the entertaining aspect of a Web site more important than most other benefits, which the exception of interactivity. Entertainment and interactivity seem to have a similar effect (in terms of size), elicited by consumers' positive affect. We conclude that consumers might perceive the interactivity of a Web site as a pleasure-oriented benefit.

\subsubsection{THEORETICAL AND MANAGERIAL IMPLICATIONS}

Many empirical studies in marketing research consider the relationship between a situation and consumer preferences (Belk 1975; Srivastava et al. 1984). Furthermore, the impact of the situation on consumers' benefit activation (salience) 
has received considerable support over the years (Gutman 1982; Warlop and Ratneshwar 1993); however, many of these studies are not very specific about the processes involved. We offer a first attempt to empirically untangle this "black box" and further understanding of the influence of the situation on consumer decision making. Specifically, we examine two mechanisms (i.e., cognitive and affective) that underlie the link between situation and benefit salience. Furthermore, measuring consumers' responses via the new information medium of the Internet extends the theoretical implications of our study. Overall, we find evidence of the cognitive route, according to which the situation has a direct influence on the benefits that are made salient in consumers' minds. However, we also find evidence of an affective route for understanding the impact of situational effects. This dual support highlights the importance of accounting for cognitive and affective effects simultaneously in understanding the effect of situation on consumers' benefit salience.

Our results also illustrate that for consumers who experience more positive affect, more benefits become salient, which may have direct managerial implications for the customization of Web sites. For instance, if consumers' emotions can be measured or influenced when they enter a Web site, the site's content could be tailored to that specific emotion (Menon and Kahn 2002). If consumers are feeling more positive, the Web site should feature a more complex design and content. In addition, knowing the affective states that get triggered by specific situations might help in Web site design. For instance, a manufacturer that knows a consumer suffers from time pressures could design a simpler Web site with fewer entertaining features. The awareness of consumers' situations and their impact on specific affective states also could help Web site designers to influence consumers' mood states which, in turn, could trigger further information search behavior among them (e.g., time and/or money spent on the site).

\subsubsection{LIMITATIONS AND DIRECTIONS FOR FURTHER RESEARCH}

Although we find support for our manipulations, additional research could apply more extreme manipulations. For instance, the time pressure situation could be manipulated differently and more directly by confronting respondents with time 
pressures as part of the experiment rather than through hypothetical scenarios. Furthermore, this study focuses on two key affective states. Future studies could consider the impact of situational variation on additional or more detailed affective responses. A further extension could measure consumers' preferences for specific Web sites and assess online search behavior (e.g., number of clicks, number of sites browsed). Finally, further research should observe consumers' emotions directly (e.g., facial expressions) rather than relying on consumers' self-reported perceptions of their emotions. 



\section{Chapter $4^{8}$}

\section{PERSONALIZED HEALTH RECOMMENDATION SYSTEMS: CONSUMER BENEFIT TRADE-OFFS ACROSS SYSTEM STAGES AND CHANNEL CONTEXTS}

This study investigates consumer perspectives on complex, multistage systems designed to provide personalized health recommendations. It conceptualizes the underlying benefit trade-offs that consumers make in evaluating such systems as the manifestation of a psychological contract in which consumers contribute their personal information and effort in exchange for a more useful, tailored recommendation by the firm. We hypothesize that consumer benefit perceptions are affected differently by the different stages in a personalized health recommendation system. In particular, we expect that benefit perceptions of usefulness, ease of use, and enjoyment are less strongly affected by stages with high levels of consumer autonomy than perceived privacy safety. In addition, we hypothesize how the channel context in which the use of a personalized health recommendation system originates (medical vs. non-medical) moderates the impact of consumer benefit perceptions on consumer willingness to use a personalized health recommendation system. We test the proposed conceptualization and hypotheses in an empirical study of personalized nutrition recommendation systems.

\footnotetext{
${ }^{8}$ Next to Sonja Wendel and Benedict G.C. Dellaert, Amber Ronteltap, and Hans C.M. van Trijp contributed to this research.
} 


\subsection{INTRODUCTION}

Increasingly, consumers in the rich economies of the world are confronted with the difficulty of maintaining a healthy life style in an affluent society. The temptation of immediate gratification, for example by eating unhealthy but tasty food or adopting low physical impact activity patterns, is hard to resist and may have serious health consequences. Over the past decade, one especially promising way proposed to assist consumers in overcoming this apparent conflict between their day-to-day consumption patterns and long-term health goals is to provide them with personalized recommendations (Kreuter et al. 1999). More specifically, preventive health researchers have emphasized the importance of personalized recommendations to support individual consumers in their efforts to successfully adopt healthier eating habits (Brug, Oenema, and Campbell 2003), stop smoking (Dijkstra et al. 1998), and become more physically active (van Sluijs et al. 2005).

Only little is known, however, about what drives consumers' willingness to use personalized health recommendation systems in the first place. This question is important because the observed beneficial effects of personalized health recommendations can only be realized with the successful adoption of such systems by consumers. Although conceptual frameworks have been proposed to classify different stages in personalization processes from the firm's perspective (e.g., Adomavicius and Tuzhilin 2005; Murthi and Sarkar 2003), it is not clear if, and if so, how, consumers take into account these stages in determining their willingness to use personalized health recommendation systems.

To address this question, we conceptualize the underlying benefit trade-offs that consumers make in evaluating such systems as the manifestation of a psychological contract in which consumers contribute personal information and effort in exchange for a more useful, tailored recommendation by the firm (Rousseau 1989). We expect that consumers mentally perform benefit trade-offs to determine which type of personalized health recommendation system provides them with the greatest value (Zeithaml 1988). To investigate these trade-offs, we define four perceived benefits (usefulness, ease of use, enjoyment, and privacy safety) that 
we expect consumers take into account when jointly evaluating the different stages of complex personal health recommendation systems (Rogers 2003).

First, we investigate how consumers' benefit perceptions are affected by different stages of personalized health recommendation systems. Personalized health recommendation systems require input from both consumers and firms, and we hypothesize that the level of consumer autonomy in a given stage is an important determinant of the strength with which this stage influences consumers' benefit perceptions. Specifically, we expect that consumers are overly optimistic about the quality, efficiency, and pleasure connected with their own contributions to personalized health recommendation systems (Metcalfe 1998; Pelletier et al. 2001). As a consequence, consumers' benefit perceptions of usefulness, ease of use, and enjoyment, may be less strongly affected by system variations in stages for which they themselves are responsible than by variations in other stages.

Second, we address consumers' benefit trade-offs that determine their willingness to use a personalized health recommendation system. Previous research shows that benefit trade-offs may vary depending on the situation in which consumers are introduced to a product or service (Srivastava, Alpert, and Shocker 1984; Wendel and Dellaert 2005). We anticipate that in the context of personalized health recommendation systems, a key situational factor that affects consumer benefit trade-offs is the channel through which the system is introduced. In particular, we hypothesize that when the system is introduced to consumers through a medical channel (e.g., suggested by their general practitioner), their benefit tradeoffs shift to relatively more usefulness- and less enjoyment-oriented compared with when the system is introduced through traditional marketing channels (e.g., commercial advertising) (e.g., Novak, Hoffman, and Duhachek 2003; Stearns et al. 2000).

We test the proposed conceptualization and hypotheses in the area of nutrition, a subfield within the health sector in which personalized recommendations are beginning to be implemented in real markets, and thus offer a very promising tool to assist consumers in their decision making (e.g., Brug et al. 2003). Our findings provide guidance to manufacturers and public health policymakers wishing to promote the use of personalized health recommendations by consumers, as well 
as to consumers, who may find that they overestimate their own ability (or underestimate the effort involved) to implement the recommendations provided by personalized health recommendation systems.

\subsection{Consumer Perspectives on Personalized Health RECOMMENDATION SYSTEMS}

\subsubsection{CONSUMER BENEFIT TRADE-OFFS}

Consumers expect different products or services to provide them with different benefits (i.e., advantages that they expect to experience from using such a product) (e.g., Gutman 1982; Myers 1976) and mentally perform benefit trade-offs to determine which alternative provides them with the greatest value (e.g., Zeithaml 1988). We propose that a comparable structure can be identified that connects the features of personalized health recommendation systems to the underlying benefits that consumers perceive these systems to have.

More specifically, we conceptualize the underlying benefit trade-offs that consumers make in evaluating personalized health recommendation systems as the manifestation of a type of psychological contract in which consumers contribute personal information and effort in exchange for a more useful, tailored recommendation by the firm. Psychological contract theory was developed mostly in the organization literature to describe individuals' beliefs in the reciprocal obligations between employees and organizations (Robinson 1996; Rousseau 1989). In the context of personalized health recommendations, a similar structure of expectations between the consumer and the firm may exist when the consumer perceives that the input he or she provides obligates the firm to return a higher quality, tailored recommendation. Thus at the core of this expectation is a consumer trade-off between the anticipated usefulness of the personalized health recommendation and the required input from the consumer.

Not surprisingly, the usefulness to the individual of a new technology, or the degree to which a person believes that using a personalized health recommendation system is beneficial in achieving the desired health outcomes, is an 
important benefit in the consumer evaluation of many new technologies (e.g., Davis, Bagozzi, and Warshaw 1989; Rogers 2003). With the proliferation of technology and the Internet, this benefit has been explored with regard to many different enduser information technologies relevant for the context of personalized health recommendations (e.g., Childers et al. 2001; Moon and Kim 2001).

In exchange for greater usefulness, consumers need to provide information to the firm that allows the firm to formulate personalized recommendations. Providing this information typically requires considerable effort on the part of the consumer, particularly in the context of health-related recommendations. Therefore, the degree to which a person believes that using a system will be free of effort (ease of use) constitutes an important second benefit that consumers are expected to consider (e.g., Davis 1989). A third benefit that may alleviate the anticipated effort by the consumer is the anticipated enjoyment of using the personalized health recommendation system. In research on technology-based self-service, Dabholkar and Bagozzi (2002) demonstrate that enjoyment significantly influences consumers' attitude toward using a technology-based self-service. Findings by Van der Heijden (2003) provide further support for the impact of perceived enjoyment on consumers' attitude in the context of Web site evaluations. Therefore, we expect that enjoyment, which we define as the degree to which a person believes that using a personalized health recommendation system will be an enjoyable experience, will also affect consumers' willingness to use such a system.

Finally, providing health information is not only costly in terms of effort to the consumer but also involves the potential risk of misuse of the information by the firm. Therefore, the degree to which a personalized health recommendation system is believed to be safe in terms of providing sensitive information (i.e., privacy safety) constitutes the fourth benefit component that we propose consumers take into account in the context of personalized health recommendation systems. Consumers are very concerned about their privacy when it comes to health-related services and are generally reluctant to provide personal information (e.g., Phelps, Nowak, and Ferrell 2000; Rabino 2003). Recent trends in information technology that enable companies to collect more and more accurate and detailed personal information likely have increased consumers' privacy concerns even more (Koch and Möslein 
2005) and made them increasingly hesitant to provide detailed personal information. The level of information required for personalized health recommendations typically is very detailed and personal, which may further aggravate privacy concerns. For example, consumers have been found to be relatively more reluctant to share their financial details than information about their lifestyle with others (Phelps et al. 2000).

\subsubsection{Stages of Personalized HeAlth ReCOMMENDATION SYSTEMS}

Previously, researchers have suggested various basic stages in the process by which firms develop personalized products and recommendations, particularly in the area of information management. Murthi and Sarkar (2003) conceptualize the personalization process in three stages: (1) learning (the supply chain collects data from the consumers), (2) matching (using consumer data, the supply chain develops a personalized offering), and (3) evaluation (the consumer assesses the effectiveness of the matching and learning stages). Adomavicius and Tuzhilin (2005) develop a similar three-stage structure that distinguishes a first stage aimed at understanding the consumer, a second stage in which the personalized offering is delivered, and a third stage that measures the impact of personalization in terms of increased consumer satisfaction. Finally, Ives and Mason (1990) suggest the so-called "customer service life cycle" as a basis for delivering personalized services. The steps in the customer service life cycle pertain to four stages a consumer must traverse in his or her acquisition and use of a product: requirement (formulating product requirements), acquisition (purchasing the product), ownership (use of the product), and retirement (reflection on the product and process).

Our analysis addresses the consumer perspective on these stages. We refine and adapt the proposed conceptual models into eight different stages in the personalized health recommendation process and explicitly highlight the consumer role in the process (Figure 4-1). An important characteristic of personalized health recommendation systems is that the object of recommendations shifts away from products or services that consumers may purchase toward recommendations about the consumers' own behavior, such as personal daily eating habits, and how this behavior may be changed (e.g., Brug et al. 2003; van Sluijs et al. 2005). This aspect 
further emphasizes the importance of the consumer's role in successfully implementing personalized health recommendations.

\section{Figure 4-1 The Structure of Personalized Health Recommendation Systems}

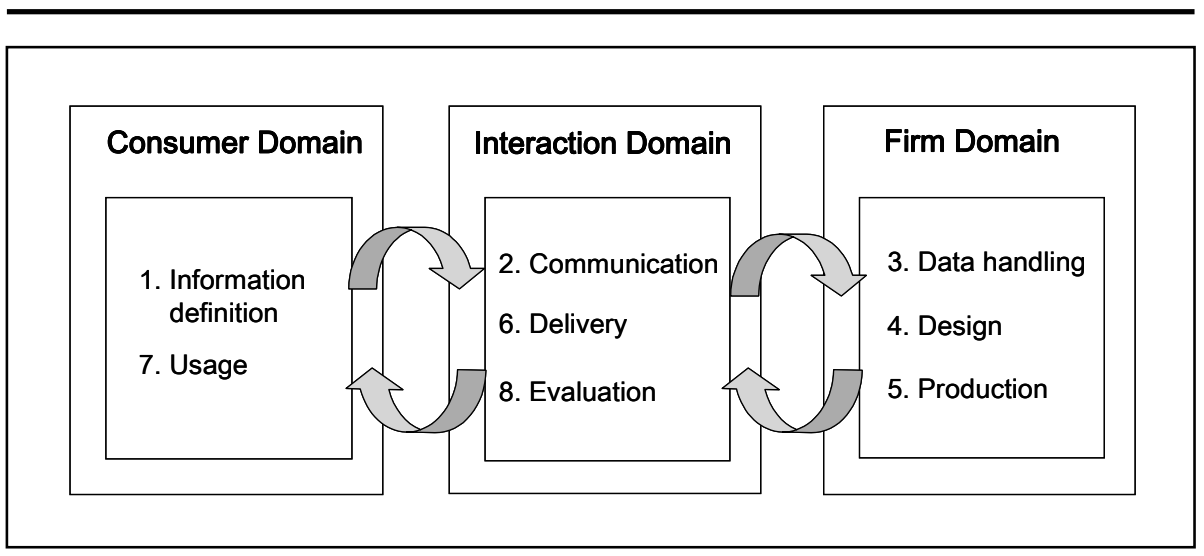

At a general level, the proposed stages can be classified in terms of three task domains: (1) the consumer domain, (2) the consumer-firm interaction domain, and (3) the firm domain. The consumer domain refers to those stages that only or mainly involve actions by the consumer (e.g., defining the relevant personal information). The consumer-firm interaction domain comprises the processes by which consumer and firm interact through various interfaces. Finally, the firm domain refers to the value-creation process undertaken by the firm on the basis of the consumer's personal information (e.g., offering a personalized solution).

In more detail, in the first stage of the personalized health recommendation process, consumers define personal information (e.g., current health condition, consumption habits) as input for the system to provide personalized feedback (stage 1: information definition). In the next stage, this information passes through an interface by which consumers and firm interact (e.g., a physical interface like a kiosk or service desk, a digital interface such as an electronic questionnaire) (stage 2: communication). Stages 3 and 4 of the process (data handling and design) pertain to the firm that transforms the personal information into a personalized solution on 
the basis of a decision model. Using the decision model, the firm next creates a personalized health recommendation that addresses the needs of a particular consumer (stage 5: production). In stage 6 (delivery), consumers and the firm interact again when the personalized health recommendation is communicated and/or distributed via a user interface and received by the consumer (e.g., through email advice). The consumer then acts on the recommendation (stage 7: usage). Finally, consumer and firm work together to evaluate the value of the health recommendation, and assess any personal improvements that occurred (stage 8: evaluation). After this stage, the consumer may or may not decide to enter the personalized health recommendation process a second time.

Personalized health recommendation systems require input both from consumers and firms, and all eight stages are required to create, deliver, and implement personalized health recommendations successfully. Therefore, we expect that the different stages jointly determine the perceived consumer benefits of personalized health recommendation systems.

We also anticipate however that the degree to which consumers are autonomous in their actions and decisions in a given stage is an important determinant of the strength of the impact of that stage on consumers' benefit perceptions. The reason is that when consumers are relatively autonomous in a given stage, this emphasizes the role of their own contribution in that stage, and we expect that consumers are more likely to evoke usage contexts and tasks in memory with which they are familiar. Because consumers are generally overly optimistic about their own skills and abilities (Metcalfe 1998) and use familiarity as a cue for ability (Schwartz and Metcalfe 1992), we expect that for stages with greater autonomy, consumers will also be overly optimistic about the quality and efficiency of their contributions in personalized health recommendation systems. Therefore, we hypothesize that consumers' benefit perceptions of usefulness and ease of use are less strongly affected by system variations for the system stages for which consumers themselves are responsible than in other stages. Likewise, we expect that though greater consumer autonomy in general increases enjoyment (Deci and Ryan 1987), it will lower the impact of variations in system stages on enjoyment beliefs, because consumers likely become more intrinsically motivated and view themselves 
as more capable of self-selecting pleasurable activities in autonomous stages (Pelletier et al. 2001). This psychological process then reduces the impact of system changes on their enjoyment beliefs. Finally, for the beliefs regarding the privacy safety benefit, we anticipate that the reduction in benefit perception does not apply; even in the consumer domain stages, the consumer has no autonomy over how the firm will deal with the information that is provided (Phelps, Nowak, and Ferrell 2000; Rabino 2003), and therefore we expect that consumer concerns regarding privacy will not be lower.

H1: Consumers' benefit perceptions of a personalized health recommendation system are determined jointly by the different stages of the system.

H2: Consumers' benefit perceptions of a personalized health recommendation system's (a) usefulness, (b) ease of use, and (c) enjoyment are less affected by variations in the consumer domain stages of the system than (d) privacy safety.

\subsubsection{Channel Context and Benefit Trade-OffS}

Consumers' benefit perceptions determine their willingness to use a personalized health recommendation system (Rogers 2003; see Figure 4-2). Previous research has shown however that the benefit trade-offs that consumers make may be context-dependent (e.g., Srivastava et al. 1984; Wendel and Dellaert 2005). There is also evidence that consumer choice in the health domain may differ depending on whether products are prescribed by physicians or are available over the counter (e.g., Hoy 1994; Ling, Berndt, and Kyle 2002; Trussell et al. 1993). 


\section{Figure 4-2 Consumer Willingness to Use Personalized Health Recommendation Systems}

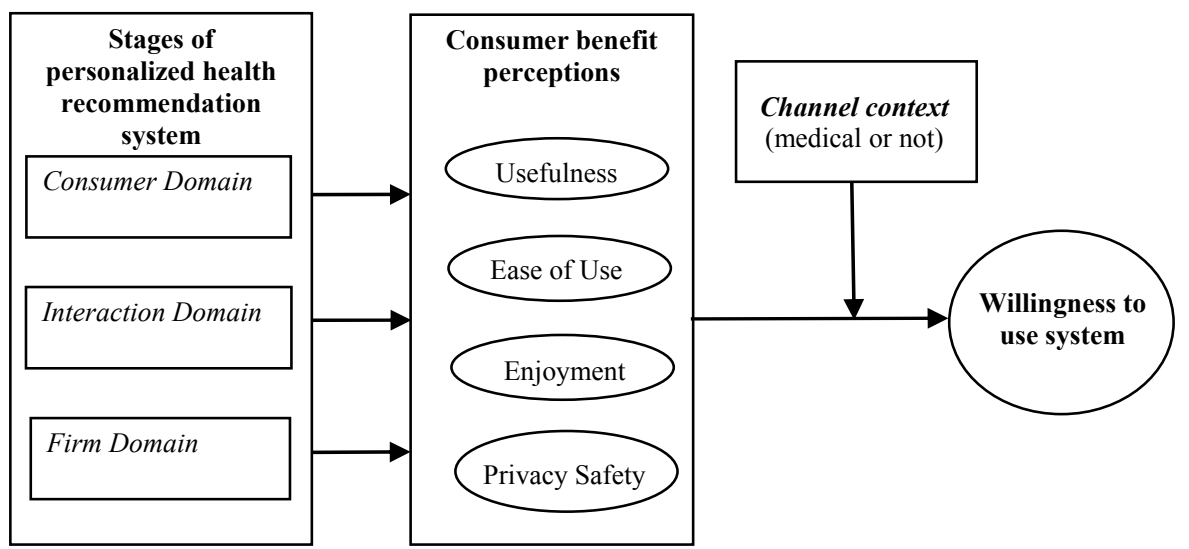

Given this context-dependent nature of consumer benefit trade-offs and choice, we anticipate that consumers' willingness to use personalized health recommendation systems may also depend on whether they are introduced to the system in a medical channel context. More specifically, we expect that a personalized health recommendation system may be regarded by consumers mainly as a means to an end, in which case they will be extrinsically motivated to use the system, if they are introduced to it in a medical channel context (e.g., using a system because of a doctor's recommendation with the aim to achieve better health). In contrast, when introduced to the system in a traditional marketing context, consumers may internalize the goal of using the system and be more likely to view using the personalized health recommendation system as a consumption experience in its own right (e.g., to explore new, healthier food options).

Previous research has noted the effect of extrinsic versus intrinsic motivation on people's purchase decisions (e.g., Bloch and Richins 1983) and technology adoption decisions (e.g., Davis, Bagozzi, and Warshaw 1992). A recent literature review by Novak et al. (2003) illustrates the coherence of this distinction through several related consumer behavior categorizations suggested by the literature. One of the main differences between the two categories stems from the lower goal orientation and stronger emphasis on experiential evaluations for 
intrinsically motivated behaviors (e.g., Mathwick, Malhotra, and Rigdon 2002). The distinction between utilitarian and hedonic goals in consumer choice behavior also has been correlated with extrinsically and intrinsically motivated behavior, respectively (e.g., Babin, Darden, and Griffin 1994).

A similar shift from a utilitarian to an experiential focus may be relevant in the context of our research. Based on the expected differences in motivation between medical and non-medical usage decisions, we hypothesize that for consumers who are introduced to the personalized health recommendation system in a medical channel context, the usefulness of the system constitutes a more important benefit than for those consumers who are introduced to the system in a traditional marketing context. In the latter case, we expect consumers to regard enjoyment as a more important benefit in determining their willingness to use the system.

H3: Consumers' willingness to use a personalized health recommendation system is affected (a) more strongly by usefulness, and (b) less strongly by enjoyment when the system is introduced in a medical context than when it is introduced in a traditional marketing context.

\subsection{Method ANd DATA}

Nutrition represents a key subsection of the health sector in which personalized recommendations have been implemented and offers a particularly promising tool to assist consumers in their decision making (e.g., Brug et al. 2003). Practical health policy decisions also are beginning to rely on personalized recommendations, as evidenced by the recent launch in 2005 of www.mypyramid.gov, a Web site that allows people to obtain a personalized diet plan based on their age, gender, and daily physical activities. More advanced commercial applications of personalized nutrition recommendations also exist, such as Sciona (www.sciona.com), a company that has developed and introduced geneticbased consumer diagnostic products like the Nutrition Screen. A toolkit, known as Sciona's Cellf Genetic Assessment, enables consumers to collect their own DNA sample at home by rubbing the inside of their cheek with a set of swabs included in 
the kit. After they complete a questionnaire about their daily eating and lifestyle habits, consumers mail the whole package to the company. Two to three weeks later, the consumer receives a 100-page personal report that evaluates his or her current lifestyle and provides nutrition behavior recommendations tailored to the consumer's genetic makeup and current lifestyle. We test our hypotheses in a similar application. In particular, we asked consumers to evaluate hypothetical scenarios of how they could interact with a supply chain to obtain personalized recommendations on how to improve their health by changing their food intake and meal preparation.

\subsubsection{SCENARIO DEVELOPMENT}

The first step in our research was to develop an in-depth, qualitative understanding of experts' and consumers' views about how to provide consumers with specific behavior recommendations and tailored food and nutrition intake advice. On the basis of extensive discussions with experts from academia and business, we developed operationalizations of personalized health recommendation systems that include the eight stages of the exchange process (Figure 4-1) and are defined in terms of the three most realistic options per stage (see Table 4-1). In the information definition stage, consumers were told what type of information they needed to provide to receive a personalized recommendation. The communication stage referred to the marketing channel through which the consumer was able to provide his or her personal information. The data handling stage indicated how the consumer's information was shared in the personalized health recommendation system. The design stage described what organization generated the personalized recommendation. The production stage of the exchange process presented consumers with different personalized solutions to match their particular needs. How these solutions were communicated to the consumer was mentioned in the delivery stage. In the following usage stage, situations were presented to consumers to describe how they could implement the recommendations. Finally, the evaluation stage indicated how consumers could evaluate the effect of the recommendations provided by the system.

We pretested the options and stages in a qualitative pilot study with 11 consumers, mainly university employees, who were not involved in the field of 
health or life sciences marketing. With these participants, we conducted individual open interviews during which we discussed the realism and relevance of the stages and options, as well as their interpretations and comprehension. We encouraged the participants to think aloud and elaborate on the stage options and any potential interactions between the options of the different stages. ${ }^{9}$ Moreover, we probed them for channel - driven motivations that might change their evaluations of different benefits and could be relevant for inclusion in the study design. On the basis of these interviews, we refined and finalized the proposed options for each stage, as we present in Table 4-1.

The interviews also resulted in our formulation of two channel contexts for the main survey, in which participants evaluated different complete personalized health recommendation systems. The medical context scenario read as follows: "You went to your doctor for your regular check-up and your doctor advised you that you would feel better if you would use a service that gives personalized recommendations about healthy eating and cooking," whereas the non-medical scenario was: "Someone you know has mentioned to you that it is possible to obtain personalized recommendations about healthy eating and cooking and you would like to try this service."

\footnotetext{
9 Participants indicated one key potential interaction, namely, between the type of personalized information available and the integrity of the data handling by the firm. Therefore, we allowed for this interaction in the hypothetical scenarios constructed for the main survey. In the estimations, however, this interaction effect is insignificant, and therefore, we exclude it from the reported results.
} 


\section{Table 4-1 Labels for Personalized Health Recommendation System Evaluation Task}

\begin{tabular}{|c|c|c|c|c|c|}
\hline Stage & Labels & Domain & Stage & Labels & Domain \\
\hline 1 & $\begin{array}{l}\text { Information definition } \\
\text { - Blood composition } \\
\text { - DNA/genetic makeup } \\
\text { - Food consumption } \\
\text { habits }\end{array}$ & Consumer & 5 & $\begin{array}{l}\text { Production of personalized } \\
\text { solution } \\
\text { - Recommendation at the } \\
\text { ingredient level } \\
\text { - Recommendation at the } \\
\text { food product group } \\
\text { level } \\
\text { - Recommendation of } \\
\text { special branded } \\
\text { products }\end{array}$ & Firm \\
\hline 2 & $\begin{array}{l}\text { Communication } \\
\text { - Through fitness club } \\
\text { - Through hospital } \\
\text { - Through general } \\
\text { practitioner }\end{array}$ & Interaction & 6 & $\begin{array}{l}\text { Delivery of personalized } \\
\text { solution/advice } \\
\text { - Through e-mail } \\
\text { - Through fitness club } \\
\text { - Through general } \\
\quad \text { practitioner }\end{array}$ & Interaction \\
\hline 3 & $\begin{array}{l}\text { Data handling by } \\
\text { recipient } \\
\text { - Fully anonymous } \\
\text { - Shared between } \\
\text { patient and general } \\
\text { practitioner } \\
\text { - Available to } \\
\text { commercial food } \\
\text { companies }\end{array}$ & Firm & 7 & $\begin{array}{l}\text { Usage } \\
\text { - Incorporated in usual } \\
\text { meal patterns } \\
\text { - Specific products added } \\
\text { to regular meals } \\
\text { - } \begin{array}{l}\text { Requiring preparation } \\
\text { of individualized } \\
\text { adjusted meals }\end{array}\end{array}$ & Consumer \\
\hline 4 & $\begin{array}{l}\text { Design: translation into } \\
\text { personalized solution } \\
\text { - By commercial food } \\
\text { company } \\
\text { - By insurance } \\
\text { company } \\
\text { - By governmental } \\
\text { nutrition center }\end{array}$ & Firm & 8 & $\begin{array}{l}\text { Evaluation opportunities } \\
\text { provided by system } \\
\text { - No feedback for } \\
\text { verification } \\
\text { - Option for feedback for } \\
\text { verification } \\
\text { - Obligatory feedback for } \\
\text { verification }\end{array}$ & Interaction \\
\hline
\end{tabular}

\subsubsection{SCALE ITEMS}

We next conducted a pretest in which respondents evaluated different options for different stages of personalized health recommendation systems with a paper-and-pencil survey. We drew scale items to measure willingness to use the system from previous research, and to measure benefits, we chose relevant items 
from existing scales that were adaptable to our context. The objective of the pretest was to validate the scale items from the literature for use in the empirical context of our research. For the survey, we randomly assigned the respondents, 108 graduate and undergraduate students who received minimal monetary compensation for participating, to three personalized health recommendation system stages, for which they evaluated three options each in terms of their perceived benefits and their willingness to use the system for each option. The evaluation measures all use ninepoint semantic differential scales.

The results of the reliability analysis confirm that the scale items drawn from the literature performed well to very well in the empirical context of our study, with Cronbach's alphas ranging from .87 to .94 . The exceptions were two items from the usefulness scale that we excluded on the basis of their low item-to-total correlations. This approach therefore determined the scale items we selected for use in the main survey. We measured usefulness with three items (Suh and Han 2002) that asked whether the system (1) was not useful/useful, (2) was not useful/useful to improve nutrition, and (3) would not/would influence purchases. For ease of use, we also employed three measures (Moon and Kim 2001) that indicated whether the system for personalized health recommendations (1) was difficult/easy to understand, (2) was difficult/easy to learn how to use, and (3) made it difficult/easy to remember what to do. Similarly, the three enjoyment measurement items (Dabholkar and Bagozzi 2002) indicated whether the system was (1) not interesting/interesting, (2) not entertaining/entertaining, and (3) not enjoyable/enjoyable. To address the system's privacy safety, we asked respondents to respond to the following three items (O'Cass and Fenech 2003): (1) I feel insecure/secure about giving up personal information, (2) I feel insecure/secure about giving up information about my health, and (3) the system is not safe/safe. Finally, for willingness to use, we used two semantic differential scales in which subjects could indicate whether it were likely/unlikely or possible/impossible that they would use the particular system for personalized health recommendations (Dabholkar and Bagozzi 2002). 


\subsubsection{Main Study: SAMPLE AND PRocedure}

After we had developed the scenario and completed the pretest, we continued to the data collection stage, which was managed by a professional market research agency that recruited 204 respondents from a large, ongoing consumer panel in the Netherlands. Respondents were invited to the central test facility for a computer-based task, which constituted part of a larger survey that took an average of one hour to complete. The sample distribution of gender was 50.5\% women and $46.1 \%$ men (3.4\% missing) with an average age of 38.3 years, ranging from 18 to 64 years. Of the respondents, $44.9 \%$ completed a higher education degree (Bachelor degree or higher). Furthermore, $22.4 \%$ lived alone, $31.1 \%$ lived in a household of two, and $46.4 \%$ lived in a household of three or more people. In the computer-based task, respondents evaluated three randomly selected scenarios from a full factorial design of all options for all stages ( $3^{8}$ full factorial). The average occurrence of an option was 204 times; with a maximum occurrence of 220 times for no feedback and a minimum of 177 times for obligatory feedback. This illustrates that the various options were shown just about equally across the scenarios. The scenarios depicted hypothetical personalized health recommendation systems, each of which offered a full profile description of the eight stages identified in Figure 4-1, defined by one of its three options. For the instructions, respondents were randomly assigned to one of two groups in which the introductions described their (hypothetical) channel context for using the personalized behavior recommendation system. ${ }^{10}$ Respondents' evaluations involved ratings of all benefit items and their willingness to use the system items for each scenario. Thus, we obtain a total of $612(3 \times 204$ respondents $)$ complete scenario evaluations, split equally across the channel contexts (medical vs. non-medical).

\subsubsection{ANALYSIS APPROACH}

First, we determine whether the different stages in the personalized health recommendation system jointly determine the benefit evaluations of the system and

\footnotetext{
${ }^{10} \mathrm{We}$ also included three scale items in the survey to measure the perceived realism of the task. The items all had average ratings above 3 on a 5-point Likert-type scale (disagree to agree), which indicates that respondents considered the task realistic.
} 
whether the variation in stages in the consumers' domain have less impact on the benefits of usefulness, ease of use, and enjoyment, than on privacy safety as we hypothesized in $\mathrm{H} 1$ and $\mathrm{H} 2$, respectively. To test these hypotheses, we estimate four regression models that capture the effect of the different options for the different stages on each of the benefits of the system. We capture the independent variables by a vector of the specific options used for each stage, and the benefits as dependent variables. We apply a fixed-effect model specification for the regressions to allow for unexplained heterogeneity, the repeated measures nature of the data (i.e., three scenario evaluations observed for each person), and the fact that different respondents saw random sets of scenarios, which potentially may have had different average benefit scores. Thus, we express the benefit perceptions $B_{i b}$ for individual $i$ for benefit $b$ as follows:

$$
B_{i b}=\alpha_{i b}^{B}+\boldsymbol{\beta}_{\mathbf{b}}^{\mathbf{B}} \mathbf{X}_{\mathbf{s}}+\varepsilon_{s i b}^{B}
$$

where, $\alpha_{i b}^{B}$ is the benefit-specific fixed effect for individual $i, \boldsymbol{\beta}_{\mathbf{b}}^{\mathbf{B}}$ is the benefit-specific vector of parameters indicating the effects of the personalized health recommendation system stage of system $s\left(\mathbf{X}_{\mathbf{s}}\right)$ on consumers benefit perception, and $\varepsilon_{s i b}^{B}$ is an error term that is assumed to be independently normal distributed. We test $\mathrm{H} 1$ by investigating if parameter estimates for multiple stages are significant. If this is the case we find support for the hypothesis that multiple stages jointly affect each benefit. We test $\mathrm{H} 2$ by comparing the parameter estimates in the consumer domain stages for usefulness, ease of use, and enjoyment, to those for privacy safety. If their (absolute) effect is smaller than that for privacy safety we find support for $\mathrm{H} 2$.

Second, to capture the hypothesized interaction effect of the channel context (medical versus non-medical) on consumers' willingness to use the system (H3), we also estimate a fixed-effect regression model. The dependent variable in this model is consumer $i$ 's willingness to use a given personalized health recommendation system $s\left(U_{s i}\right)$. We use the following independent variables: An individual-specific intercept $\alpha_{i}^{U}$ that is constant for each respondent and does not 
vary across the personalized health recommendation systems that he or she evaluates, an individual-specific vector of system benefit perceptions $\mathbf{B}_{\mathbf{s i}}$, and the vector $\boldsymbol{\beta}^{\mathbf{U}}$ that expresses the effect of each benefit perception on the consumer's willingness to use the system. To test $\mathrm{H} 3$, we also include a channel dummy $C$ that interacts with benefit perceptions, and the parameter vector for this interaction term $(\boldsymbol{\theta})$. If the parameters in this vector for usefulness and enjoyment are significant and have signs as expected we find support for $\mathrm{H} 3 \mathrm{a}$ and $\mathrm{H} 3 \mathrm{~b}$ respectively. Finally, we include an error term $\varepsilon_{s i}^{U}$ to capture any remaining unexplained variation. We assume the errors are independently and identically normal distributed. Therefore,

$$
U_{s i}=\alpha_{i}^{U}+\boldsymbol{\beta}^{\mathbf{U}} \mathbf{B}_{\mathbf{s i}}+\boldsymbol{\theta} \mathbf{B}_{\mathbf{s i}} C+\varepsilon_{s i}^{U}
$$

\subsection{RESULTS}

\subsubsection{ScAle Performance}

We first examine whether the items used to measure the four consumer benefits and willingness to use the system may be measuring the same underlying construct or are related but distinct benefits. The fit of the one-factor model is very bad $\left(\chi^{2}(77)=3264.37, p<.001\right.$; comparative fit index $[\mathrm{CFI}]=.70$, nonnormed fit index $[\mathrm{NNFI}]=$ Tucker-Lewis index $[\mathrm{TLI}]=.64$, root mean square error of approximation $[\mathrm{RMSEA}]=.26$, and adjusted goodness-of-fit index [AGFI] $=.40$ ). Thus, the one-factor model clearly is rejected. Next, we estimate the hypothesized five-factor model, which provides a good fit $\left(\chi^{2}(67)=204.93, p<.001 ; \mathrm{CFI}=.98\right.$, $\mathrm{NNFI}=\mathrm{TLI}=.98, \mathrm{RMSEA}=.059$, and AGFI $=.93)$. Moreover, the fit of the fivefactor model is dramatically and significantly $\left(\Delta \chi^{2}=3059.44, p<.001\right)$ better than that of the one-factor model. All factor loadings are significant ( $\mathrm{t}$-values greater than 13.86), and all completely standardized loadings are greater than .56, with an average of .84 . These findings support the convergent validity of the measures. Cronbach's alphas are $.80, .88, .88, .90$, and .93 for usefulness, ease of use, enjoyment, privacy safety, and willingness to use the system, respectively. We 
follow the approach by Fornell and Larcker (1981) to test the discriminant validity of our measures, which states that the average variance extracted (AVE) of a latent construct must be greater than the squared correlations with other latent constructs. The estimates of the AVE are .82, .71, .82, .85, and .93 for ease of use, usefulness, enjoyment, privacy safety, and willingness to use the system respectively and exceed the squared correlation of these constructs. We therefore obtain a composite score for each construct by averaging the appropriate scale items.

\subsubsection{HYPOTHESES TESTING}

The results for $\mathrm{H} 1$ and $\mathrm{H} 2$ are displayed in Table 4-2, which shows the effect of the different options for each stage on the benefits of the system. The results show that options in stages from all three domains significantly influence consumers' benefits perceptions of the system, providing support for H1.

The results in Table 4-2 also show if for the consumer domain (i.e., information definition, usage, and evaluation) the benefits usefulness, ease of use, and enjoyment are impacted less strongly by changes in stage options than the privacy safety benefit (H2). For the information definition stage, we find that usefulness, ease of use, and enjoyment are unaffected by changes in stage options, whereas privacy safety is affected. This result provides support for H2. For the usage stage the results are inconclusive, because none of the benefit perceptions are significantly affected by changes in the stage options.

H3 hypothesized that the impact of usefulness and enjoyment on consumer willingness to use a personalized health recommendation system is moderated by consumers' channel context (medical vs. non-medical). To test this hypothesis, we conduct an analysis in which we allow for an interaction of the channel context and system benefits usefulness and enjoyment along with the main effects of the system benefits. The results of this test are reported in Table 4-3 (second column) and provide support for the hypothesis that the effect of usefulness on willingness to use the system is greater when the personalized health recommendation system is 
introduced in a medical channel context $(\beta=.13, p<.01)$, whereas the effect of enjoyment is smaller $(\beta=-.10, p<.05) .{ }^{11}$

The main effects of consumers' benefit perceptions are also shown in Table 4-3 (column 2) and indicate that consumer perceptions of benefits are strong predictors of consumer willingness to use a personalized behavior recommendation system $\left(\mathrm{R}^{2}{ }_{\text {adj }}=.71, p<.001\right)$. Although greater ease of use does not increase consumers' willingness to use a personalized health behavior recommendation system, greater usefulness has a significant effect $(p<.001)$. Also, greater enjoyment is a strong and significant predictor of consumers' willingness to use the system $(p<.001)$. Furthermore, consumers' willingness to use the system significantly increases with greater privacy safety $(p<.001)$.

\footnotetext{
${ }^{11}$ We used the following coding: $1=$ medical channel context, $0=$ traditional marketing context.
} 
$\begin{array}{ll}\text { Table 4-2 } & \text { Effects of Personalized Health Recommendation } \\ & \text { System Stages on Benefit Perceptions (H1 and H2) }\end{array}$

\begin{tabular}{|c|c|c|c|c|c|}
\hline & Domain & Usefulness & Ease of Use & Enjoyment & $\begin{array}{c}\text { Privacy } \\
\text { Safety }\end{array}$ \\
\hline $\begin{array}{l}\text { 1. Information definition: Base } \\
=\text { Blood composition }\end{array}$ & Consumer & & & & \\
\hline DNA/genetic makeup & & -.04 & -.06 & -.06 & $-.11 *$ \\
\hline Food consumption habits & & .06 & .04 & .08 & $.13^{*}$ \\
\hline $\begin{array}{l}\text { 2. } \text { Communication: } \text { Base }= \\
\text { Fitness club }\end{array}$ & Interaction & & & & \\
\hline Through general practitioner & & $.24 * *$ & $.15 * *$ & $.21 * *$ & $.23 * *$ \\
\hline Through hospital & & $.17^{* *}$ & $.10^{*}$ & .11 & $.18 * *$ \\
\hline $\begin{array}{l}\text { 3. Data handling: Base }= \\
\text { Fully anonymous }\end{array}$ & Firm & & & & \\
\hline $\begin{array}{l}\text { Shared with patient and } \\
\text { general practitioner }\end{array}$ & & -.01 & .04 & .04 & .07 \\
\hline $\begin{array}{l}\text { Available to commercial food } \\
\text { company }\end{array}$ & & -.08 & -.06 & -.10 & $-.14 *$ \\
\hline $\begin{array}{l}\text { 4. Design: Base }=\text { Commercial } \\
\text { food company }\end{array}$ & Firm & & & & \\
\hline Insurance Company & & $-.17 * *$ & -.07 & $-.18 * *$ & $-.13 *$ \\
\hline $\begin{array}{l}\text { Governmental nutritional } \\
\text { center }\end{array}$ & & -.05 & .02 & -.04 & .08 \\
\hline $\begin{array}{l}\text { 5. Production: Base }= \\
\text { Ingredients }\end{array}$ & Firm & & & & \\
\hline Product groups & & .06 & $.09 *$ & $.14 *$ & .08 \\
\hline Product brands & & -.11 & .01 & -.08 & .02 \\
\hline $\begin{array}{l}\text { 6. Delivery: Base }= \\
\text { Through e-mail }\end{array}$ & Interaction & & & & \\
\hline Through fitness club & & $-.17 * *$ & $-.10 *$ & $-.18^{* *}$ & $-.13 *$ \\
\hline Through general practitioner & & .01 & -.03 & -.10 & -.06 \\
\hline 7. Usage: Base $=$ Usual meal & Consumer & & & & \\
\hline Addition to regular meal & & -.04 & .00 & -.02 & -.01 \\
\hline Separate cooking & & -.06 & -.08 & -.05 & .04 \\
\hline $\begin{array}{l}\text { 8. Evaluation: Base }=\text { No } \\
\text { feedback }\end{array}$ & Interaction & & & & \\
\hline Optional feedback & & $.19 * *$ & $.15^{* *}$ & $.17 * *$ & $.18^{* *}$ \\
\hline Obligatory feedback & & .09 & $.12 *$ & $.13^{*}$ & $.13^{*}$ \\
\hline Model Fit & & $\mathrm{R}^{2}=.33$ & $\mathrm{R}^{2}=.58$ & $\mathrm{R}^{2}=.30$ & $\mathrm{R}^{2}=.43$ \\
\hline
\end{tabular}

£ Estimates of regression model with individual-specific fixed effects.

* $\quad$ Significant at $p<.05$.

** Significant at $p<.01$. 


\section{Table 4-3 Effects of Benefit Perceptions on Willingness to Use a Personalized Health Recommendation System (H3) ${ }^{\text {f }}$}

\begin{tabular}{|c|c|c|c|}
\hline & $\begin{array}{c}\text { Benefits } \\
\text { Model }\end{array}$ & $\begin{array}{c}\text { System Stages } \\
\text { Model }\end{array}$ & $\begin{array}{c}\text { Benefits and } \\
\text { System Stages }\end{array}$ \\
\hline Usefulness & $.30^{* *}$ & & $.30^{* *}$ \\
\hline Ease of use & .00 & & .00 \\
\hline Enjoyment & $.46^{* *}$ & & $.46^{* *}$ \\
\hline Privacy safety & $.20 * *$ & & $.20 * *$ \\
\hline $\begin{array}{l}\text { Impact of medical channel on the } \\
\text { effect of usefulness }\end{array}$ & $.13^{* *}$ & & $.13 * *$ \\
\hline $\begin{array}{l}\text { Impact of medical channel on the } \\
\text { effect of enjoyment }\end{array}$ & $-.10^{*}$ & & -.09 \\
\hline \multirow{2}{*}{\multicolumn{4}{|c|}{$\begin{array}{l}\text { 1. Information definition: } \text { Base }= \\
\text { Blood composition }\end{array}$}} \\
\hline & & & \\
\hline DNA/genetic makeup & & -.10 & -.04 \\
\hline Food consumption habits & & .05 & -.03 \\
\hline \multicolumn{4}{|l|}{$\begin{array}{l}\text { 2. Communication: Base }= \\
\text { Fitness club }\end{array}$} \\
\hline Through general practitioner & & $.16^{* *}$ & -.05 \\
\hline Through hospital & & .09 & -.04 \\
\hline \multicolumn{4}{|l|}{$\begin{array}{l}\text { 3. Data handling: Base }=\text { Fully } \\
\text { anonymous }\end{array}$} \\
\hline $\begin{array}{l}\text { Shared with patient and } \\
\text { general practitioner }\end{array}$ & & -.01 & -.04 \\
\hline $\begin{array}{l}\text { Available to commercial } \\
\text { food company }\end{array}$ & & $-.16^{* *}$ & $-.07 *$ \\
\hline \multicolumn{4}{|l|}{$\begin{array}{l}\text { 4. Design: } \text { Base }=\text { Commercial } \\
\text { food company }\end{array}$} \\
\hline Insurance company & & $-.20 * *$ & -.04 \\
\hline $\begin{array}{l}\text { Governmental nutritional } \\
\text { center }\end{array}$ & & -.03 & -.03 \\
\hline \multicolumn{4}{|l|}{ 5. Production: Base $=$ Ingredients } \\
\hline Product groups & & .07 & -.04 \\
\hline Product brands & & -.11 & -.05 \\
\hline \multicolumn{4}{|l|}{$\begin{array}{l}\text { 6. Delivery: Base = } \\
\text { Through e-mail }\end{array}$} \\
\hline Through fitness club & & $-.19 * *$ & -.03 \\
\hline Through general practitioner & & -.07 & -.02 \\
\hline \multicolumn{4}{|l|}{ 7. Usage: Base $=$ Usual meal } \\
\hline Addition to regular meal & & .01 & .04 \\
\hline Separate cooking & & .00 & .04 \\
\hline \multicolumn{4}{|l|}{ 8. Evaluation: Base $=$ No feedback } \\
\hline Optional feedback & & $.14^{*}$ & -.02 \\
\hline Obligatory feedback & & $.13^{*}$ & .02 \\
\hline Model Fit & $\mathrm{R}^{2}=.81$ & $\mathrm{R}^{2}=.38$ & $\mathrm{R}^{2}=.81$ \\
\hline
\end{tabular}

£ Estimates of regression model with individual-specific fixed effects

* $\quad$ Significant at $\mathrm{p}<.05$

** $\quad$ Significant at $\mathrm{p}<.01$ 


\subsubsection{FURTHER ANALYSES}

We conducted further analyses to investigate the expected mediation effect of personalized health recommendation system stages on consumers' willingness to use the system through system benefits. We also explore if the insignificant effect of ease of use on consumers' willingness to use such a system could be explained by a second mediation effect, in which the impact of ease of use on consumers' willingness to use a system is mediated by its perceived usefulness. At least partial mediation of the effect of ease of use has been suggested in previous research (e.g., Davis, Bagozzi, and Warshaw 1989).

Following Baron and Kenny's (1986) mediation analysis, we had to conduct two extra analyses that capture (1) consumers' willingness to use a personalized health recommendation system as a function of the system's options per stage and (2) consumers' willingness to use a personalized health recommendation system as a joint function of the system's options per stage and its benefits. Partial mediation occurs when the effect of the options per stage is significantly lower when we include benefits in the model, whereas full mediation implies that the effect of options is no longer significant with the addition of benefits.

We display these results in Table 4-3 (columns 3 and 4). First, we find that options in several of the stages in the consumer (evaluation), consumer-firm interaction (communication and delivery), and firm (data handling, design, and production) domains contribute significantly $(p<.05)$ to the explanation of consumers' willingness to use a personalized health recommendation system (column 3). Mediation is demonstrated (e.g., Baron and Kenny 1986) if the independent variables (system options) exert significant effects on the mediator (system benefits), as well as the dependent variable (consumers' willingness to use the system), but the effect of the system options on consumers' willingness to use is significantly reduced when the mediating variable is incorporated as a covariate. We report the results of the regression model that includes both benefit and system option variables in Table 4-3 (column 4). All except one effect of system options become insignificant when system benefits are included as covariates; the exception 
is if personal information is made available to a commercial food company. Thus, we find evidence for full mediation for all but one system stage.

To investigate the surprising result that ease of use does not affect consumers' willingness to use a personalized health recommendation system, we conducted a second mediation analysis. In previous studies, the effect of ease of use has also been ambiguous (e.g., Taylor and Todd 1995), and it was suggested that this might be the case because ease of use cannot always be fully separated from usefulness in consumers' perceptions, and that greater ease of use increases usefulness. Therefore, we also conduct a Baron and Kenny mediation test to explore if the effect of ease of use on consumer willingness to use a personalized health recommendation system is mediated by the perceived usefulness of the system. First, we eliminate usefulness in the willingness to use model. The estimates show that ease of use now is significant at $p<.001$. Second, we estimate a regression model in relating ease of use to usefulness and find a significant positive effect at $p$ $<.001$. As a result, we conclude that there is indeed a mediation effect of ease of use on consumers' willingness to use a personalized health recommendation system through usefulness, which explains our finding of no effect of ease of use on willingness to use a personalized health recommendation system.

\subsection{CONCLUSION AND DISCUSSION}

We have developed and tested a model of consumers' evaluations of personalized health recommendation systems that was based on the underlying idea of a psychological contract between the consumer and the firm. In our application to personalized nutritional advice, we find empirical support for the three key contentions of our model, namely, H1: different stages jointly affect consumers' benefit perceptions of the system; H2: consumers' benefit perceptions of usefulness, ease of use, and enjoyment are affected less than privacy safety by stage options in the information definition stage, while in the usage stage none of the benefit perceptions are affected by system options, and H3: the channel context (medical vs. non-medical) affects consumers' benefit trade-offs in determining their willingness to use the personalized health recommendation system. 
More generally, we find support for the fact that consumers' benefit perceptions of a personalized health recommendation system are driven jointly by the different stages of the system, some of which occur in the domain of the consumer, some in the domain of the firm, and some in the consumer-firm interaction domain. Thus, firms that promote such a system to potential customers should consider the multiple stages of such a system in communicating and promoting personalized health recommendations. However, we also find the two stages in the consumer domain (i.e., information definition, and usage) do not affect the perceived benefits usefulness, ease of use, and enjoyment. Therefore, options in these stages appear to be less important in marketing personalized health recommendation systems.

Importantly, we find that the consumer-firm interaction domain plays a crucial role in how consumers evaluate personalized health recommendation systems. Consumers prefer communication through their general practitioner compared to a fitness club and dislike delivery by a fitness club as compared to an email delivery. The evaluation stage also has very clear and significant implications for the system's benefit perceptions, which suggests that consumers view evaluations as an important aspect of personalized health recommendation stages. Accordingly, it is crucial for firms that are planning to implement such a system to consider how and where to make this system accessible in terms of useful interfaces. To a lesser extent, but also vital is the firm domain. Foremost, this outcome illustrates that it is important for firms to make this information available to consumers (e.g., what companies are involved in this process). More specifically, consumers dislike data handling if it is available to commercial food companies, do not favor designs by insurance companies, and disfavor production when it is specified in terms of branded food products. Somewhat more speculatively, these findings illustrate consumers' reluctance for commercial applications of personalized health recommendation systems. Apparently, consumers prefer options that have traditionally operated in the not-for-profit domain.

Also significant and in line with previous studies (e.g., Henneman, Timmermans, and van der Wal 2004), we find that the general practitioner can play a key role in personal information definition. Unlike other services, health-related 
personalized recommendation systems rely on endorsements by the medical sector, and less medically-oriented delivery options, such as through a fitness center, are less appealing, possibly because non-medical parties may not be able to provide the necessary reassurance to consumers. In turn, this finding has considerable implications for the distribution and communication channels for health-oriented personalized recommendation systems, which may be relatively hard to implement outside traditional health service channels.

Furthermore, our results show that the channel context through which the personalized health recommendation system is introduced also plays an important role in the benefits that could be emphasized and promoted to consumers in the introduction phase of a personalized health recommendation system. The usefulness and value of utilizing such a system would be most beneficial to stress in a medical channel context (i.e., a general practitioner advises to use the system), whereas the enjoyment of a system is more relevant when the system is introduced in a traditional marketing context (e.g., when consumers are curious to try out a new system that they have seen in a commercial).

Our results also suggest some type of classification of consumers' benefittrade-off. On the one hand, we observe that ease of use, usefulness, and enjoyment are differentially affected by the various stages of the system. On the other hand, we examine that privacy safety of the system is pervasive throughout consumers' evaluation of the system across the different domains and stages. Thus, since consumers evaluate the system based on its privacy safety almost independent of the stage options, this aspect is crucial for firms to stress in their communication and promotion of such a system. Our study applied scenarios describing personalized health recommendation systems and it would be interesting to investigate whether similar results hold up in consumers' evaluations of real-world personalized health recommendation systems.

More generally, behavior-oriented recommendations such as those in health recommendations typically imply real one-to-one marketing that uniquely identifies and addresses each consumer. To a great extent, this very intimate identification is key to optimizing and tailoring recommendations, but at the same time, it may trigger greater consumer concerns about privacy safety. Thus, such systems confront 
a trade-off between usefulness and privacy safety: Lower privacy safety implies greater usefulness through more tailored recommendations. This trade-off poses a major challenge for marketing personalized health behavior recommendations. Therefore, we hope that our study provides a contribution in developing new insights at the intersection of marketing and health sciences, in particular into how best to assist consumers in adopting systems that allow them to develop healthier consumption patterns. 

Chapter 5

CONCLUSION 
"The proviso that 'it depends upon the situation' is a general acknowledgement of the expected consonance of behavior and the settings in which it takes place."

-Belk 1974, 156

\section{$5.1 \quad$ SYNOPSIS}

"It depends upon the situation" is a well-known phrase heard often in everyday life. To understand this situational phenomenon, many marketing researchers have addressed the implications of this phrase. In particular, early work by Belk $(1974,1975)$ engages this subject matter precisely and explores the concept of situation and its implications for consumer behavior. We build on this early work by also addressing the importance of thinking contextually in the field of consumerfirm communications. The influence of situation in this context, to the best of our knowledge, largely has been overlooked in the field of marketing. The increase in the number of communication channels (e.g., new media such as the Internet) accessible to consumers for retrieving a variety of information (e.g., tracking orders, finding product information) makes such an analysis particularly challenging and relevant. Therefore, this dissertation addresses the following research question:

\section{What is the effect of situation on when and how consumers prefer to connect with firms in the communication process?}

This central research question appears throughout three interrelated studies, presented in Chapters 2, 3, and 4. In the first study, described in Chapter 2, we develop a model to investigate consumers' media channel consideration across various usage situations and show the importance that the usage situation and consumers' perceived media channel benefits have for consumers' considerations of a particular channel. In a follow-up study, reported in Chapter 2, we further explore the process by which situation drives consumers' benefit importance. We identify two joint routes (affective and cognitive), which are complementary in nature, that explain this underlying mechanism. Study 3, as discussed in Chapter 4, explores 
consumers' evaluations of the consumer-firm interactions designed to create and deliver personalized health recommendations. We argue that channel context (medical versus non-medical) is an essential driver that moderates the relationship between consumers' benefit evaluations and their use of a personalized health recommendation system. Thus, throughout this dissertation, situation serves as a key variable that links consumers and firms in the communication process.

This final chapter of the dissertation provides an overview of the major results of these three studies, addresses its theoretical and managerial contributions, and closes with additional suggestions for further research.

\subsection{Situational Variation in Consumers' Media Channel CONSIDERATION}

In the first study, we explore direct and indirect routes by which the usage situation affects consumers' media channel considerations. We pay particularly attention to the media channels that consumers find acceptable when they search for food product information. To theorize about consumers' considerations, we take a cost-benefit approach (Roberts and Nedungadi 1995) across three usage situations, presented as hypothetical scenarios. According to the cost-benefit approach, a consumer considers a particular media channel if the benefits of including this channel within his or her consideration set exceed his or her individual consideration threshold (e.g., cognitive costs) (Bronnenberg and Vanhonacker 1996). We posit that consumers actively decide what media channel(s) to include in their consideration sets and, on the basis of the substitution-in-use (SIU) approach (Srivastava et al. 1981), suggest that consumers look for benefits that media channels provide, just as they would for products, and that the usage situation determines these benefits.

Our results show that the usage situation affects the media channels that consumers consider. In our model, we focus on the overall effects of the usage situation on consumers' media channel considerations and required benefits, but we do not make specific predictions about the directions of the effects (e.g., the 
channels that might be considered in a specific usage situation). Usage situation has a direct effect on the benefits that consumers require a media channel to possess, their perceptions of channel benefits have a direct effect on their media channel considerations, and this latter effect is moderated by the benefits required by the usage situation. In summary, these results illustrate that theory regarding consideration set formation is applicable to the context of media channel considerations. Furthermore, in theorizing about the effect of the situation on benefits and channel consideration, we validate the SIU approach. Thus, companies that can think in customer scenarios (usage situations) likely will be better able to meet the information needs of their consumers.

\subsection{CONSUmer Benefit SALience}

The results of study 1 provide evidence that consumers' required benefits change according to the usage situation. In study 2, discussed in Chapter 3, we follow up on these results and further explore the underlying mechanism by which benefits shift depending on situation. The context pertains to consumers' information search behavior for food products via the Internet. Specifically, we focus on the impact of two situational dimensions identified by Belk (1975) - a time factor and a social factor - that we manipulate. Our goal is to understand how the usage situation affects consumers' benefit importance, as well as the number of benefits that become salient. We identify two routes, an affective route and a cognitive route, through which this process might operate.

\subsubsection{AFFECTIVE RoUTE}

Various researchers confirm the strong influence of emotional responses on consumer decision making (e.g., Bagozzi, Gopinath, and Nyer 1999) and have focused particularly on the issue of affective responses (i.e., pleasure and arousal) and their effects on consumer behavior (e.g., information processing). In study 2, we build on this work by considering consumers' positive affect, which we manipulate by inducing pleasure. Research shows that consumers who experience positive affect are more open, willing, and elaborative in processing information (Isen 2001). 
The results of our study support these claims, and we illustrate that more benefits become salient for people who experience positive affect. Paralleling theories about positive affect and consumer decision making, we find support for our hypothesis that consumers in positive affective states focus on more pleasure-oriented benefits to maintain their good moods.

\subsubsection{Cognitive Route}

Scholars have also attended to the cognitive processes that take place in consumers' minds to explore the impact of situation on consumer decision-making processes (Warlop and Ratneshwar 1993). We therefore suggest a second (direct) route that links the usage situation and consumers' benefit salience. First, on the basis of the premise that consumers have limited working memory capabilities (Bettman 1979), we argue that consumers retrieve only a bundle (or subset) of benefits from memory when they are confronted with a specific usage situation. As a result, we hypothesize that, after we control for affect, the number of salient benefits will be limited but not vary across usage situations. However, we find that consumers who experience social pressure find fewer benefits salient. This outcome might occur because consumers in this condition are unable to retrieve information directly from their memory (possibly because they are not as familiar with a social pressure situation as they would be with a time pressure situation).

We also investigate if the usage situation triggers the relative importance of salient benefits. For this investigation, we rely on research about memory-based effects (e.g., Weber and Johnson 2006), which argues that consumers call upon their prior experiences from memory (unconsciously or consciously), triggered by the usage situation. Thus, depending on the usage situation, the benefits that become salient in consumers' minds will differ.

In summary, with this study we make a first attempt to understand the processes that take place in consumers' minds and thereby explain the impact of usage situations on benefit salience. Furthermore, we apply our framework in the context of a new information medium, which means our study provides a further substantive contribution. Our findings are particularly relevant in terms of the customization of companies' Web sites. For instance, because customers who are in 
a more positive mood are more likely to value the entertaining aspects of a Web site, firms should attempt to create a match between entertaining features and consumers' needs. Again, companies that are able to put themselves in the shoes (i.e., situations) of their customers will be able to address their needs more easily and effectively.

\subsection{Consumer Benefit Trade-Offs ACross System Stages and Channel Contexts}

A starting point for our final study was consumers' growing awareness, triggered by the media as well as academic research, of the dangers of unhealthy lifestyles (Moorman and Matulich 1993). Preventive health researchers have proposed that personalized recommendations could be helpful tools in assisting consumers to live healthier lives (Brug, Oenema, and Campbell 2003). In response, in our final study, we explore the drivers and motivations of consumers to adopt a personalized health recommendation system in the context of nutritional food products. This study represents a first attempt to understand and explain consumers' adoption of personalized health recommendation systems. Therefore, we start off by identifying the benefits that consumers take into account when they evaluate such systems, then extend our analysis by building on personalization research (Murthi and Sarkar 2003) and investigating how different stages in the process affect consumers' benefit evaluations. Furthermore, we argue that the channel context plays a key role in consumers' willingness to use personalized recommendation systems.

We show that consumers indeed consider multiple stages when they evaluate a system such as the one we created. Enjoyment, usefulness, and privacy safety all increase consumers' willingness to use a personalized recommendation system. As we anticipated, the channel context also plays a significant role, such that consumers in a medical channel condition value the usefulness of the system more, whereas consumers in a traditional marketing channel consider enjoyment of the system more important. Overall, the results illustrate that consumers are hesitant when it comes to commercial applications in this domain (e.g., data available to 
commercial food companies, designs prepared by insurance companies, delivery by fitness clubs). In contrast, general health practitioners can play a crucial role in making personalized health recommendations acceptable. This interesting and demanding finding has major implications for how health-related personalized recommendation systems might best be introduced to consumers.

\subsection{LIMITATIONS AND FUTURE RESEARCH SUGGESTIONS}

The final part of this concluding chapter offers some limitations of the studies presented in the previous chapters and provides general perspectives about research that could provide further insights into the effects of usage situation on consumer-firm communications.

Situational variables help predict consumer behavior and consumer decision making. The main discussions of the taxonomy of situation go back to the 1970s, and since then, Belk's (1975) classification of situation has been adopted by many researchers in the field of marketing, even though Belk himself encouraged additional research to conceptualize consumer situations. Thus, ongoing research should address precisely this aspect of situation. For instance, the category "task definition," as identified by Belk, appears to be the most commonly adopted aspect of situation in existing studies, perhaps because the concept of task in itself already captures a broad range of relevant situational aspects that might be disentangled by additional research. In the area of consumer information retrieval, for example, an emergency situation might be classified separately from a less urgent situation. This issue also could be relevant in the context of the channels consumers consider to obtain information. Furthermore, and partly in line with the previous suggestion, consumers' level of involvement in a situation might trigger specific behavior (e.g., channel choice, benefit salience); therefore, researchers should attempt to identify and compare less involving situations (e.g., just browsing on the Internet) with more involving situations (e.g., information retrieval in case of a food scare).

In study 1 we investigated a general model of how the usage situation influences the media channels that consumers consider during their search for product information; additional research might attempt to formulate more precise 
suppositions about these effects. Just as Srivastava et al. (1981) created clusters of financial services across various usage situations, other researchers could apply this approach and cluster media channels on the basis of the usage situations that consumers find appropriate. Moreover, it might be interesting to investigate if (and how) situational dimensions drive the use of specific media channels, though a prerequisite for such a study would be the ability to manipulate all five situational dimensions. One assumption of our first study is that consumers follow a costbenefit approach in forming a consideration set of possible media channels in their search for product information. Yet, consumers might consider a media channel based on habitual behavior and not rationally evaluate all the options available to them. Thus, habit might be a potential driver of consumers' information search processes. Particularly an investigation of the relationships between environmental influences (for instance specific usage situations), habits, and consumer decision making in terms of information acquisition could be a promising future research.

All three studies described in this dissertation are cross-sectional in nature, so a complementary longitudinal study of consumers' use and consideration of media channels across various situations would provide interesting insights, including, for example, an identification of consumer multichannel usage. For instance, in the health context, a longitudinal study designed to capture consumers' information search behavior over time and the choices that are made could provide promising insights. This could for instance be implemented by asking respondents who have been diagnosed with a specific disease to record their weekly search behavior and possible choices made (e.g., on medication or hospital). Moreover, it would be interesting to track the use of channels across various situations, such as information search, product use behavior (e.g., your digital TV box has just arrived, and you need help to install it), complaint behavior, or compliance behavior (certainly applicable in the health sector).

Thus, in summary, we hope that the research presented in this dissertation provides new insights into consumers' responses to different situations in the context of communications and also offers some useful starting points for additional research in this area. 


\section{REFERENCES}


Adomavicius, Gediminas and Alexander Tuzhilin (2005), "Personalization Technologies: A Process-Oriented Perspective," Communications of the ACM, 48 (October), 83-90.

Andrews, Rick L. and T.C. Srinivasan (1995), "Studying Consideration Effects in Empirical Choice Models Using Scanner Panel Data," Journal of Marketing Research, 32 (February), 30-41.

Ansari, Asim, Skander Essegaier, and Rajeev Kohli (2000), "Internet Recommendation Systems," Journal of Marketing Research, 37 (August), 36375.

Babin, Barry J., William R. Darden, and Mitch Griffin (1994), "Work and/or Fun: Measuring Hedonic and Utilitarian Shopping Value," Journal of Consumer Research, 20 (March), 644-56.

Bagozzi, Richard P., Mahesh Gopinath, and Prashanth U. Nyer (1999), "The Role of Emotions in Marketing," Journal of the Academy of Marketing Science, 27 (Spring), 184-206.

Baker, Julie, Michael Levy, and Dhruv Grewal (1992), “An Experimental Approach to Making Retail Store Environmental Decisions," Journal of Retailing, 68 (Winter), 445-60.

Baron, Reuben M. and David A. Kenny (1986), “The Moderator-Mediator Variable Distinction in Social Psychological Research: Conceptual, Strategic, and Statistical Considerations," Journal of Personality \& Social Psychology, 51 (6), 1173-82.

Belk, Russel W. (1974), “An Exploratory Assessment of Situational Effects in Buyer Behavior,” Journal of Marketing Research, 11 (May), 156-63.

- (1975), “Situational Variables and Consumer Behavior," Journal of Consumer Research, 2 (December), 157-64.

Bettman, James R. (1979), An Information Processing Theory of Consumer Choice, Reading, MA: Addison Wesley.

Bloch, Peter H. and Marsha L. Richins (1983), “A Theoretical Model for the Study of Product Importance Perceptions," Journal of Marketing, 47 (Summer), 6981. 
Bronnenberg, Bart J. and Wilfried R. Vanhonacker (1996), "Limited Choice Sets, Local Price Response, and Implied Measures of Price Competition," Journal of Marketing Research, 33 (May), 163-73.

Brown, Juanita J. and Albert R. Wildt (1992), "Consideration Set Measurement," Journal of the Academy of Marketing Science, 20 (Summer), 235-43.

Brug, Johannes, Anke Oenema, and Marci Campbell (2003), "Past, Present and Future of Computer-Tailored Nutrition Education," American Journal of Clinical Nutrition, 77 (April), 1028S-34S.

Childs, Nancy M. and Gregg H. Poryzees (1997), "Foods that Help Prevent Disease: Consumer Attitudes and Public Policy Implications," Journal of Consumer Marketing, 14 (6), 433-47.

Childers, Terry L., Christopher L. Carr, Joann Peck, and Stephen Carson (2001), "Hedonic and Utilitarian Motivations for Online Retail Shopping Behavior," Journal of Retailing, 77 (Winter), 511-35.

Dabholkar, Pratibhar and Richard P. Bagozzi (2002), “An Attitudinal Model of Technology-Based Self-Service: Moderating Effects of Consumer Traits and Situational Factors," Journal of the Academy of Marketing Science, 30 (Summer), 184-201.

Davis, Fred D. (1989), "Perceived Usefulness, Perceived Use, and User Acceptance of Information Technology," MIS Quarterly, 13 (September), 319-40.

, Richard P. Bagozzi, and Paul R. Warshaw (1989), "User Acceptance of Computer Technology: A Comparison of Two Theoretical Models," Management Science, 35 (August), 982-1003.

$\longrightarrow$ - $\longrightarrow$, and (1992), “Extrinsic and Intrinsic Motivation to Use Computers in the Workplace," Journal of Applied Social Psychology, 22, 111132.

Deci, Edward L. and Richard M. Ryan (1987), "The Support of Autonomy and the Control of Behavior," Journal of Personality and Social Psychology, 53 (6), 1024-37.

Desai, Kalpesh K. and Wayne D. Hoyer (2000), "Descriptive Characteristics of Memory-Based Consideration Sets: Influence of Usage Occasion Frequency 
and Usage Location Familiarity," Journal of Consumer Research, 27 (December), 309-23.

Diehl, Kristin, Laura J. Kornish, and John G. Lynch (2003), "Smart Agents: When Lower Search Costs for Quality Information Increase Price Sensitivity," Journal of Consumer Research, 30 (June), 56-71.

Dijkstra, Arie, Hein de Vries, Jolanda Roijackers, and Gerard van Breukelen (1998),

“Tailoring Information to Enhance Quitting in Smokers with Low Motivation to Quit: Three Basic Efficacy Questions," Health Psychology, 17 (6), 513-19.

Donovan, Robert J. and John R. Rossiter (1982), "Store Atmosphere: An Environmental Psychology Approach,” Journal of Retailing, 58 (Spring), 3457.

Fornell, Claes and David F. Larcker (1981), "Evaluating Structural Equation Models with Unobservable Variables and Measurement Error," Journal of Marketing Research, 18 (February), 39-50.

Gardner, Meryl P. (1985), "Mood States and Consumer Behavior: A Critical Review," Journal of Consumer Research, 12 (December), 281-300.

Ghosh, Shikhar (1998), "Making Business Sense of the Internet," Harvard Business Review, 76 (March/April), 126-35.

Gutman, Jonathan (1982), “A Means-End Model Based on Consumer Categorization Processes," Journal of Marketing, 46 (Spring), 60-72.

Haeckel, Stephan H. (1998), "About the Nature and Future of Interactive Marketing," Journal of Interactive Marketing, 12 (Winter), 63-71.

Häubl, Gerald and Valerie Trifts (2000), “Consumer Decision Making in Online Shopping Environments: The Effects of Interactive Decision Aids," Marketing Science, 19 (Winter), 4-21.

Hauser, John R. and Birger Wernerfelt (1990), “An Evaluation Cost Model of Consideration Sets," Journal of Consumer Research, 16 (March), 393-408.

Henneman, Lidewij, Danielle R.M. Timmermans, and Gerrit van der Wal (2004), "Public Experiences, Knowledge and Expectations about Medical Genetics and the Use of Genetic Information," Community Genetics, 7, 33-43.

Hong, Sung-Tai and Robert S. Wyer (1990), "Determinants of Product Evaluation: Effects of the Time Interval between Knowledge of a Product's Country of 
Origin and Information about Its Specific Attributes," Journal of Consumer Research, 17 (December), 277-88.

Houston, Mark B. and Beth A. Walker (1996), "Self-Relevance and Purchase Goals:

Mapping a Consumer Decision," Journal of the Academy of Marketing Science, 24 (Summer), 232-45.

Hoy, Mariea G. (1994), “Switch Drugs Vis-à-Vis Rx and OTC: Policy, Marketing, and Research Considerations," Journal of Public Policy \& Marketing, 13 (Spring), 85-96.

Hoyer, Wayne D. and Steven P. Brown (1990), "Effects of Brand Awareness on Choice for a Common, Repeat-Purchase Product," Journal of Consumer Research, 17 (September), 141-48.

Huffman, Cynthia and Barbara E. Kahn (1998), "Variety for Sale: Mass Customization or Mass Confusion?” Journal of Retailing, 74 (Winter), 491-513. Isen, Alice M. (2001), “An Influence of Positive Affect on Decision Making in Complex Situations: Theoretical Issues with Practical Implications," Journal of Consumer Psychology, 11 (2), 75-85. and Nehemia Geva (1987), "The Influence of Positive Affect on Acceptable Level of Risk: The Person with a Large Canoe Has a Large Worry," Organizational Behavior and Human Decision Processes, 39 (April), 145-54.

Ives, Blake and Richard O. Mason (1990), "Can Information Technology Revitalize Your Customer Service?" Academy of Management Executive, 4 (November), 52-69.

Kahn, Barbara E. and Alice M. Isen (1993), "The Influence of Positive Affect on Variety Seeking Among Safe, Enjoyable Products," Journal of Consumer Research, 20 (September), 257-70.

Kenny, David and John F. Marshall (2000), “Contextual Marketing: The Real Business of the Internet," Harvard Business Review, 78 (November/December), 119-25.

Koch, Michael and Kathrin M. Möslein (2005), "Identities Management for ECommerce and Collaboration Applications," International Journal of Electronic Commerce, 9 (Spring), 11-29. 
Kreuter, Matthew W., David Farell, Laura Olevitch, and Laura K. Brennan (1999), Tailored Health Messages: Customizing Communication with Computer Technology. Mahwah, NJ: Lawrence Erlbaum Associates.

Lindell, Michael K. and David J. Whitney (2001), "Accounting for Common Method Variance in Cross-Sectional Research Designs," Journal of Applied Psychology, 86 (February), 114-21.

Ling, Davina C., Ernst R. Berndt, and Margaret K. Kyle (2002), "Deregulating Direct-To-Consumer Marketing of Prescription Drugs: Effects on Prescription and Over-The-Counter Product Sales," Journal of Law \& Economics, 45 (October), 691-723.

Lodish, Leonard M., Magid Abraham, Stuart Kalmenson, Jeanne Livelsberger, Beth Lubetkin, Bruce Richardson, and Mary Ellen Stevens (1995), "How T.V. Advertising Works: A Meta-Analysis of 389 Real World Split Cable T.V. Advertising Experiments," Journal of Marketing Research, 32 (May), 125-39.

Loiacono, Eleanor T., Richard T. Watson, and Dale L. Goodhue (2002), "WEBQUAL: A Measure of Website Quality," in Marketing Theory and Applications, Winter Marketing Educators' Conference Proceedings, Vol. 13, eds. Kenneth R. Evans and Lisa K. Scheer, Chicago: American Marketing Association, 432-38.

Lutz, Richard J. and Pradeep Kakkar (1975), "The Psychological Situation as a Determinant of Consumer Behavior," in Advances in Consumer Research, Vol. 2, ed. Mary Jane Schlinger, Chicago: Association for Consumer Research, 43954.

MacKenzie, Scott B. (1986), “The Role of Attention in Mediating the Effect of Advertising on Attribute Importance," Journal of Consumer Research, 13 (September), 174-95.

Madden, Mary and Susannah Fox (2006), Findings Answers Online in Sickness and Health, The Pew Internet \& American Life Project, available online at Www.pewinternet.org/reports

Mano, Haim (1992), "Judgments under Distress: Assessing the Role of Unpleasantness and Arousal in Judgment Formation," Organizational Behavior and Human Decision Processes, 52 (July), 216-45. 
(1997), “Affect and Persuasion: The Influence of Pleasantness and Arousal on Attitude Formation and Message Elaboration," Psychology and Marketing, 14 (July), 315-35.

- and Richard L. Oliver (1993), “Assessing the Dimensionality and Structure of the Consumption Experience: Evaluation, Feeling, and Satisfaction," Journal of Consumer Research, 20 (December), 451-66.

Mathwick, Charla, Naresh Malhotra, and Edward Rigdon (2001), "Experiential Value: Conceptualization, Measurement, and Application in the Catalog and Internet Shopping Environment,” Journal of Retailing, 77 (Spring), 39-56.

(2002), "The Effect of Dynamic Retail Experiences on Experiential Perceptions of Value: An Internet and Catalog Comparison," Journal of Retailing, 78 (Spring), 51-60.

- and Edward Rigdon (2004), "Play, Flow, and the Online Search Experience,” Journal of Consumer Research, 31 (September), 324-32.

McKinney, Vicki, Kanghyun Yoon, and Fatemeh Zahedi (2002), “The Measurement of Web-Customer Satisfaction: An Expectation and Disconfirmation Approach," Information Systems Research, 13 (September), 296-315.

Mehrabian, Albert and James A. Russell (1974), An Approach to Environmental Psychology, Cambridge, MA: MIT Press.

Mehta, Nitin, Surendra Rajiv, and Kannan Srinivasan (2003), "Price Uncertainty and Consumer Search: A Structural Model of Consumer Consideration Set Formation," Marketing Science, 22 (Winter), 58-84.

Meloy, Margaret G. (2000), "Mood-Driven Distortion of Product Information," Journal of Consumer Research, 27 (December), 345-59.

Menon, Satya and Barbara E. Kahn (2002), "Cross-Category Effects of Induced Arousal and Pleasure on the Internet Shopping Experience," Journal of Retailing, 78 (Spring), 31-40.

Metcalfe, Janet (1998), “Cognitive Optimism: Self-Deception or Memory-Based Processing Heuristics?” Personality and Social Psychology Review, 2 (2), 10010. 
Miller Kenneth E. and James L. Ginter (1979), “An Investigation of Situational Variation in Brand Choice Behavior and Attitude," Journal of Marketing Research, 16 (February), 111-23.

Moon, Ji-Won and Young-Gul Kim (2001), "Extending the TAM for a WorldWide-Web Context," Information \& Management, 38 (February), 217-30.

Moorman, Christine and Erika Matulich (1993), “A Model of Consumers' Preventive Health Behaviors: The Role of Health Motivation and Health Ability," Journal of Consumer Research, 20 (September), 208-28.

Murthi, B.P.S. and Sumit Sarkar (2003), "The Role of the Management Sciences in Research on Personalization," Management Science, 49 (October), 1344-62.

Muylle, Steve, Rudy Moenaert, and Marc Despontin (2004), “The Conceptualization and Empirical Validation of Web Site User Satisfaction," Information \& Management, 41 (May), 543-60.

Myers, James H. (1976), "Benefit Structure Analysis: A New Tool for Product Planning," Journal of Marketing, 40 (October), 23-32.

Newell, Allen and Herbert A. Simon (1972), Human Problem Solving, Englewood Cliffs, NJ: Prentice-Hall.

Novak, Thomas P., Donna L. Hoffman, and Adam Duhachek (2003), “The Influence of Goal-Directed and Experiential Activities on Online Flow Experiences," Journal of Consumer Psychology, 13 (1\&2), 3-16.

O’Cass, Aron and Tino Fenech (2003), “Web Retailing Adoption: Exploring the Nature of Internet Users Web Retailing Behavior," Journal of Retailing and Consumer Services, 10 (2), 81-95.

Osgood, Charles E., George J. Suci, and Percy H. Tannenbaum (1957), The Measurement of Meaning, Urbana: University of Illinois Press.

Pelletier, Luc G., Michelle S. Fortier, Robert J. Vallerand, and Nathalie M. Brière (2001) “Associations Among Perceived Autonomy Support, Forms of SelfRegulation, and Persistence: A Prospective Study," Motivation and Emotion, 25 (4), 279-306.

Phelps, Joseph, Glen Nowak, and Elizabeth Ferrell (2000), "Privacy Concerns and Consumer Willingness to Provide Personal Information," Journal of Public Policy \& Marketing, 19 (Spring), 27-41. 
Podsakoff, Philip M., Scott B. MacKenzie, Jeong-Yeon Lee, and Nathan P. Podsakoff (2003), “Common Method Biases in Behavior Research: A Critical Review of the Literature and Recommended Remedies," Journal of Applied Psychology, 88 (October), 879-903.

Putrevu, Sanjay and Brian T. Ratchford (1997), “A Model of Search Behavior with an Application to Grocery Shopping," Journal of Retailing, 73 (Winter), 46386.

Rabino, Isaac (2003), "Genetic Testing and its Implications: Human Genetics Researchers Grapple with Ethical Issues," Science, Technology \& Human Values, 28, 365-402.

Ratchford, Brian T., Debabrata Talukdar, and Myung-Soo Lee (2001), “A Model of Consumer Choice of the Internet as an Information Source," International Journal of Electronic Commerce, 5 (Spring), 7-21.

Ratneshwar, S. and Allan D. Shocker (1991), "Situations in Use and the Role of Usage Context in Production Category Structures," Journal of Marketing Research, 28 (August), 281-95.

_ L Luk Warlop, David G. Mick, and Gail Seeger (1997), "Benefit Salience and Consumers' Selective Attention to Product Features," International Journal of Research in Marketing, 14 (July), 245-59.

Roberts, John R. and James M. Lattin (1997), “Consideration: Review of Research and Prospects for Future Insights," Journal of Marketing Research, 34 (August), 406-13. and Prakash Nedungadi (1995), "Studying Consideration in the Consumer Decision Process: Progress and Challenges," International Journal of Research in Marketing, 12 (May), 3-7.

Robinson, Sandra L. (1996), "Trust and Breach of the Psychological Contract," Administrative Science Quarterly, 41 (December), 574-99.

Rogers, Everett M. (2003), Diffusion of Innovations, 5th ed. New York: The Free Press.

Rousseau, Denise M. (1989), "Psychological and Implied Contracts in Organizations," Employee Responsibilities and Rights Journal, 2 (June), 12139. 
Russell, James A. and Albert Mehrabian (1977), "Evidence for a Three-Factor Theory of Emotions," Journal of Research in Personality, 11 (September), 27394.

Sanbonmatsu, David M. and Frank R. Kardes (1988), “The Effects of Physiological Arousal on Information Processing and Persuasion," Journal of Consumer Research, 15 (December), 379-85.

Schwartz, Barry L. and Janet Metcalfe (1992), “Cue Familiarity but not Target Retrievability Enhances Feeling-of-Knowing Judgments," Journal of Experimental Psychology: Learning, Memory and Cognition, 18 (5), 1074-83.

Seybold, Patricia B. (2001), "Get Inside the Lives of Your Customers," Harvard Business Review 79 (May), 80-90.

Sinha, Indrajit (1994), "A Conceptual Model of the Role of Situational Type on Consumer Choice Behavior and Consideration Sets," in Advances in Consumer Research, Vol. 21, ed. Chris T. Allen and Deborah Roedder John, Provo, UT: Association for Consumer Research, 477-82.

Sloan, Elizabeth A. (1999), "Top Ten Trends to Watch and Work on for the Millennium," Food Technology, 53 (8), 40-60.

Smith, Robert E. and William R. Swinyard (1982), "Information Response Models: An Integrated Approach,” Journal of Marketing, 46 (Winter), 81-93.

Srivastava, Rajendra K. (1981), “Usage-Situational Influences on Perceptions of Product-Markets: Theoretical and Empirical Issues," in Advances in Consumer Research, Vol. 8, ed. Kent B. Monroe, Ann Arbor: Association for Consumer Research, 106-11.

—, Mark L. Alpert, and Allan D. Shocker (1984), “A Customer-Oriented Approach for Determining Market Structures," Journal of Marketing, 48 (Spring), 32-45.

—, Robert P. Leone, and Allan D. Shocker (1981), "Market Structure Analysis: Hierarchical Clustering of Products based on Substitution-In-Use," Journal of Marketing, 45 (Summer), 38-48.

Stearns, Sally C., Shulamit L. Bernard, Sara B. Fasick, Robert Schwarz, Robert T. Konrad, Marcia G. Ory, and Gordon H. DeFriese (2000), "The Economic Implications of Self-Care: The Effect of Lifestyle, Functional Adaptations, and 
Medical Self-Care Among a National Sample of Medicare Beneficiaries," American Journal of Public Health, 90 (October), 1608-12.

Steckel, Joel, Russ Winer, Randy Bucklin, Benedict G.C. Dellaert, Xavier Drèze, Gerald Häubl, Sandy Jap, John Little, Tom Meyvis, Alan Montgomery, and Arvind Rangaswamy (2005), "Choice in Interactive Environments," Marketing Letters, 16 (December), 309-20.

Stewart, David W. and Paul A. Pavlou (2002), "From Consumer Response to Active Consumer: Measuring the Effectiveness of Interactive Media," Journal of the Academy of Marketing Science, 30 (Fall), 376-96.

Suh, Bomil and Ingoo Han (2002), "Effect of Trust on Customer Acceptance of Internet Banking," Electronic Commerce Research \& Applications, 1 (Autumn), 247-63.

Swait, Joffre and Wiktor Adamowicz (2001), "The Influence of Task Complexity on Consumer Choice: A Latent Class Model of Decision Strategy Switching," Journal of Consumer Research, 28 (June), 135-48.

Taylor, Shirley and Peter A. Todd (1995), “Understanding Information Technology Usage: A Test of Competing Models," Information Systems Research, 6 (June), 144-76.

Ter Hofstede, Frenkel, Anke Audenaert, Jan-Benedict E.M. Steenkamp, and Michel Wedel (1998), “An Investigation into the Association Pattern Technique as a Quantitative Approach to Measuring Means-End Analysis," International Journal of Research in Marketing, 15 (February), 37-50.

—, Jan-Benedict E.M. Steenkamp, and Michel Wedel (1999), "International Market Segmentation Based on Consumer-Product Relations," Journal of Marketing Research, 36 (February), 1-17.

Train, Kenneth E. (2003), Discrete Choice Methods with Simulation, Cambridge, UK: Cambridge University Press.

Trussell, James, Felicia Stewart, Malcolm Potts, Felicia Guest, and Charlotte Ellertson (1993), "Should Oral Contraceptives be Available without Prescription?” American Journal of Public Health, 83 (August), 1094-99. 
Van der Heijden, Hans (2003), "Factors Influencing the Usage of Websites: The Case of a Generic Portal in The Netherlands," Information \& Management, 40 (July), 541-49.

Van Kenhove, Patrick, Kristof de Wulf, and Walter van Waterschoot (1999), "The Impact of Task Definition on Store-Attribute Saliences and Store Choice," Journal of Retailing, 75 (Spring), 125-37.

Van Sluijs, Esther M.F., Mireille N.M. van Poppel, Jos W.R. Twisk, Johannes Brug, and Willem van Mechelen (2005), "The Positive Effect on Determinants of Physical Activity of a Tailored, General Practice-Based Physical Activity Intervention," Health Education Research, 20 (3), 345-56.

Warlop, Luk and S. Ratneshwar (1993), “The Role of Usage Context in Consumer Choice: A Problem Solving Perspective," in Advances in Consumer Research, Vol. 20, eds. Leigh McAlister and Michael L. Rothschild, Provo, UT: Association for Consumer Research, 377-82.

Watson, David and Auke Tellegen (1985), "Toward a Consensual Structure of Mood," Psychological Bulletin, 98 (September), 219-35.

Watson, Richard T., Pierre Berthon, Leyland F. Pitt, and George M. Zinkhan (2000), Electronic Commerce: The Strategic Perspective, Fort Worth, TX: The Dryden Press.

Weber, Elke U. and Eric J. Johnson (2006), "Constructing Preferences from Memory," in The Construction of Preference, eds. Sarah Lichtenstein and Paul Slovic, New York: Cambridge University Press, 397-410.

Wendel, Sonja and Benedict G.C. Dellaert (2005), "Situation Variation in Consumers' Media Channel Consideration," Journal of the Academy of Marketing Science, 33 (Fall), 575-84.

Westbrook, Robert A. (1987), "Product/Consumption-Based Affective Responses and Postpurchase Processes," Journal of Marketing Research, 24 (August), 258-70.

Wind, Jerry and Arvind Rangaswamy (2001), "Customerization: The Next Revolution in Mass Customization," Journal of Interactive Marketing, 15 (Winter), 13-32. 
Wolfinbarger, Mary and Mary C. Gilly (2003), “eTailQ: Dimensionalizing Measuring, and Predicting Etail Quality," Journal of Retailing, 79 (Fall), 18398.

Zeithaml, Valarie A. (1988), “Consumer Perceptions of Price, Quality, and Value: A Means-End Model and Synthesis of Evidence," Journal of Marketing, 52 (July), $2-22$.

Zinkhan, George M., Hyokjin Kwak, Michelle Morrison, and Cara O. Peters (2003), "Web-Based Chatting: Consumer Communication in Cyberspace," Journal of Consumer Psychology, 13 (1\&2), 17-27.

and Claes Fornell (1985), “A Test of Two Consumer Response Scales in Advertising," Journal of Marketing Research, 12 (November), 447-52. 

APPENDICES

$-105-$ 


\section{Appendix 3A}

\section{Scenario Descriptions for Chapter 3}

High time pressure/high social pressure

You recently made a new girlfriend and you want to impress her; therefore, you invited her for dinner at your place tomorrow night. You know that she values a healthy, low calorie dinner; therefore, you decide to search on the Internet for a recipe right now.

High time pressure/low social pressure

You agreed with one of your housemates to come to your place for dinner tomorrow night. You are searching right now on the Internet for a healthy, low calorie recipe.

Low time pressure/high social pressure

You recently made a new girlfriend and you want to impress her; therefore, you invited her for dinner at your place in two weeks. You know that she values a healthy, low calorie dinner; therefore, you decide to search on the Internet for a recipe.

Low time pressure/low social pressure

You agreed with one of your housemates to come to your place for dinner in two weeks. You are searching on the Internet for a healthy, low calorie recipe. 


\section{Appendix 3B}

\section{Benefit Scale Items of Chapter 3}

\begin{tabular}{|c|c|c|}
\hline Construct & Item Description & Reliability \\
\hline Relevance & $\begin{array}{l}\text { In this situation, I find it important that } \\
\text { the information on the web site is applicable for my objective.* } \\
\text { the information on the web site is related to my objective. } \\
\text { the information on the web site is pertinent for my objective. } \\
\text { in general, the information on the web site is relevant for my } \\
\text { objective. }\end{array}$ & $\alpha=.85$ \\
\hline Understandability & $\begin{array}{l}\text { In this situation, I find it important that } \\
\text { the information on the web site is clear in meaning.* } \\
\text { the information on the web site is easy to comprehend. } \\
\text { the information on the web site is easy to read. } \\
\text { in general, the information on the web site is understandable. }\end{array}$ & $\alpha=.90$ \\
\hline Reliability & $\begin{array}{l}\text { In this situation, I find it important that } \\
\text { the information on the web site is trustworthy. } \\
\text { the information on the web site is accurate. } \\
\text { the information on the web site is credible. } \\
\text { in general, the information on the web site is reliable. }\end{array}$ & $\alpha=.90$ \\
\hline Adequacy & $\begin{array}{l}\text { In this situation, I find it important that } \\
\text { the information on the web site is sufficient for my information } \\
\text { need. } \\
\text { the information on the web site is complete for my information } \\
\text { need.* } \\
\text { the information on the web site covers necessary topics for my } \\
\text { information need. } \\
\text { in general, the information on the web site is adequate for my } \\
\text { information need. }\end{array}$ & $\alpha=.83$ \\
\hline Scope & $\begin{array}{l}\text { In this situation, I find it important that } \\
\text { the information on the web site covers a wide range. } \\
\text { the information on the web site covers a wide variety of topics. } \\
\text { the information on the web site covers a number of different } \\
\text { topics. } \\
\text { in general, the information on the web site covers a broad scope } \\
\text { of topics.* }\end{array}$ & $\alpha=.89$ \\
\hline
\end{tabular}




\begin{tabular}{|c|c|c|}
\hline Construct & Item Description & Reliability \\
\hline Usefulness & $\begin{array}{l}\text { In this situation, I find it important that } \\
\text { the information on the web site is helpful. } \\
\text { the information on the web site is valuable for my information } \\
\text { need. } \\
\text { in general, the information on the web site is useful for my } \\
\text { information need. }\end{array}$ & $\alpha=.89$ \\
\hline Usability & $\begin{array}{l}\text { In this situation, I find it important that } \\
\text { the web site has a simple layout for its content. } \\
\text { the web site is easy to use. } \\
\text { the web site is well-organized. } \\
\text { the web site has a clear design. } \\
\text { in general, the web site is user-friendly. }\end{array}$ & $\alpha=.88$ \\
\hline Speed & $\begin{array}{l}\text { In this situation, I find it important that } \\
\text { the web site is time saving. } \\
\text { it does not take a lot of time to get from one place in the web } \\
\text { site to another. } \\
\text { the web site is fast. }\end{array}$ & $\alpha=.80$ \\
\hline Entertainment & $\begin{array}{l}\text { In this situation, I find it important that } \\
\text { the web site is entertaining. } \\
\text { the web site is catching.* } \\
\text { the web site not only provides information but also entertains } \\
\text { me. }\end{array}$ & $\alpha=.85$ \\
\hline Navigation & $\begin{array}{l}\text { In this situation, I find it important that } \\
\text { it is easy to go back and forth between web site pages. } \\
\text { with a few clicks one can locate the information. } \\
\text { it is easy to navigate on the web site. }\end{array}$ & $\alpha=.79$ \\
\hline Interactivity & $\begin{array}{l}\text { In this situation, I find it important that } \\
\text { the web site is interactive to receive tailored information. } \\
\text { the web site has interactive features, which helps me } \\
\text { accomplish my task. } \\
\text { I can communicate with the web site in order to get information } \\
\text { tailored to my specific needs. }\end{array}$ & $\alpha=.87$ \\
\hline Hyperlinks & $\begin{array}{l}\text { In this situation, I find it important that } \\
\text { the web site has an adequate number of links.* } \\
\text { the web site has clear descriptions for each link.* }\end{array}$ & n.a. \\
\hline
\end{tabular}




\begin{tabular}{|llc|}
\hline Construct & Item Description & Reliability \\
\hline Decisional control & In this situation, I find it important that & $\alpha=.88$ \\
& navigating on the web site allows me to make a lot of decision & \\
& on my own/ \\
& I have a lot to say about what happens in these online \\
& information searches. \\
& $\begin{array}{l}\text { I have flexibility in my interactions with the web site while } \\
\text { searching for information. }\end{array}$ \\
\hline
\end{tabular}

(*) indicates that this item was deleted on the basis of confirmatory factor analysis. n.a. $=$ not applicable 



\section{CURRICULUM VITAE}

Sonja Wendel was born on the $23^{\text {rd }}$ of September 1976 in Bad Dürkheim, Germany. She attended the Carl-Bosch-Gymnasium in Ludwigshafen am Rhein, Germany and received her diploma from German secondary school in 1996 after spending two years at Brick Memorial High School, New Jersey, USA, and two years at Monmouth University, New Jersey, USA. She started studying Economics at Maastricht University, The Netherlands in 1996, where she obtained her Master's degree in Economics in 2001. In 2001, she joined the Department of Marketing at Maastricht University, where she first worked seven months as a junior lecturer and then became employed as a Ph.D. candidate in 2002. During her time as a Ph.D. candidate she spent six months abroad at the University of Georgia, Athens, USA. Her research interests lie in the area of consumer decision-making, communications, and health. She is particularly interested in exploring manufacturer-consumer communications. Her work has been published in the Journal of the Academy of Marketing Science.

Since April 2006 she is working as a Post Doctoral Researcher in the field of Life Sciences at the Department of Business Economics, Erasmus University Rotterdam. 